NBER WORKING PAPER SERIES

\title{
HEALTH DISPARITIES ACROSS EDUCATION: THE ROLE OF DIFFERENTIAL REPORTING ERROR
}

\author{
John Cawley \\ Anna Choi \\ Working Paper 21317 \\ http://www.nber.org/papers/w21317 \\ NATIONAL BUREAU OF ECONOMIC RESEARCH \\ 1050 Massachusetts Avenue \\ Cambridge, MA 02138 \\ July 2015
}

For helpful comments and suggestions, we thank John Mullahy, an anonymous referee, Benjamin Cowan, Joseph Price, and participants in the American Society of Health Economists biennial conference, and the seminar of the Cornell Institute for Health Economics, Health Behaviors and Disparities. Cawley thanks the Robert Wood Johnson Foundation for its financial support through an Investigator Award in Health Policy Research. The authors have no conflicts of interest. The views expressed herein are those of the authors and do not necessarily reflect the views of the National Bureau of Economic Research.

NBER working papers are circulated for discussion and comment purposes. They have not been peer-reviewed or been subject to the review by the NBER Board of Directors that accompanies official NBER publications.

(C) 2015 by John Cawley and Anna Choi. All rights reserved. Short sections of text, not to exceed two paragraphs, may be quoted without explicit permission provided that full credit, including () notice, is given to the source. 
Health Disparities Across Education: The Role of Differential Reporting Error

John Cawley and Anna Choi

NBER Working Paper No. 21317

July 2015

JEL No. I1,I12,I14,I20,I24,I3

\begin{abstract}
$\underline{\text { ABSTRACT }}$
One of the most robust findings in health economics is that higher-educated individuals tend to be in better health. This paper tests whether health disparities across education are to some extent due to differences in reporting error across education. We test this hypothesis using data from the pooled National Health and Nutrition Examination Survey (NHANES) Continuous for 1999-2012, which include both self-reports and objective verification for an extensive set of health behaviors and conditions, including smoking, obesity, high blood pressure, high cholesterol and diabetes.

We find that college graduates are more likely to give false negative reports of obesity and high total cholesterol; one possible explanation for this is social desirability bias. However, college graduates are also significantly less likely to give false positive reports of smoking, obesity, high cholesterol, and diabetes. Because there are far more truly negative people (who are less likely to give a false positive report) than truly positive people (who are more likely to give a false negative report), we find that college graduates report their health significantly more accurately overall.
\end{abstract}

John Cawley

2312 MVR Hall

Department of Policy Analysis and Management

and Department of Economics

Cornell University

Ithaca, NY 14853

and NBER

JHC38@ cornell.edu

Anna Choi

Organization for Economic Cooperation

and Development (OECD)

ac774@cornell.edu 


\section{Introduction}

One of the most robust findings in health economics is that the higher educated tend to be in better health (Grossman and Kaestner, 1997; Cutler and Lleras-Muney, 2010; Cutler, Huang \& Llreas-Muney, 2015). This is true for many health behaviors and conditions, including smoking, drinking alcohol, obesity, exercise, and cancer screening (Cutler, Huang \& Llreas-Muney, 2015; Grossman and Kaestner, 1997).

There are several possible mechanisms for this correlation. The model of health capital (Grossman, 1972) predicts that those with more schooling will demand more health. Education may increase both allocative efficiency (i.e. the better educated may choose a healthier mix of inputs) and productive efficiency (i.e. the better educated may be able to produce more health with the same inputs). Cutler and Llreas-Muney (2010) conclude that knowledge and cognitive ability explain 30 percent, and health insurance, income, and family background account for another 30 percent, of the education gradient in health. This is consistent with earlier work that concluded that increased health knowledge explains part but not all of the relationship between education and smoking, alcohol consumption, and exercise (Kenkel, 1991).

This study tests a novel hypothesis for the correlation between education and self-reported health: differential reporting error by education. ${ }^{1}$ There are many potential sources of reporting error (see, e.g. Brener et al., 2003; Johnston et al., 2009), some of which may vary by education. For example, social desirability bias arises from respondents seeking to present a positive image to the interviewer (Edwards, 1957). As a result, the more stigmatized and negatively sanctioned the health condition or behavior, the stronger the tendency of respondents to deny it. The better educated may

\footnotetext{
${ }^{1}$ Our focus in this paper is on self-reported health. Obviously, differential reporting error cannot explain educational differences in objectively measured health.
} 
have greater awareness of medical recommendations, public health messaging, and the health consequences of these conditions or behaviors, and thus may be more embarrassed to admit engaging in unhealthy behaviors and more susceptible to social desirability bias. As a result, the better educated may underreport risky health behaviors or stigmatized conditions.

On the other hand, there are reasons to believe that the better educated may report more accurately. For example, some reporting error arises because of cognitive issues: failing to comprehend the question, having a faulty memory, or making mistakes in answering the questions (e.g. Brener et al., 2003). The better educated may be better able to comprehend and respond to survey questions and thus be less likely to make those sort of errors. In addition, some misreporting may be due to poor information, and the better educated may be more knowledgeable about their health, perhaps because they have greater access to health care or independently monitor their health more closely. Given these various sources of error, differential reporting error across education groups could lead to either an overestimate or an underestimate in educational gradients in health.

We examine a variety of health conditions and behaviors, including smoking, obesity, high blood pressure, high cholesterol, and diabetes. We examine numerous conditions and behaviors because the direction and magnitude of reporting error may differ by health condition and behavior. For example, conditions and behaviors differ in the extent to which they are socially stigmatized. It may be more embarrassing for a college graduate to report a high weight or to admit smoking than to report having high blood pressure. They also differ in the extent to which the interviewer can visually verify the report; respondents may know that they can deny having high cholesterol or high blood pressure and the interviewer will be none the wiser, but respondents may be cautious in misreporting their weight given that the interviewer observes their appearance. Conditions also differ in how much the respondents themselves know. Respondents may be unaware that they have high blood pressure and high cholesterol because they can be asymptomatic and thus may require diagnosis by a medical 
professional. In contrast, respondents know whether they are smokers because that is a conscious act. Obesity may lie somewhere in between - people may have a vague idea of their weight, but not know it exactly. A strength of this paper is that it examines a wide range of conditions and health behaviors in order to determine whether there are consistent patterns of misreporting by education.

This paper relates to a large literature that measures reporting error in health and how it varies with education. ${ }^{2}$ Some research focuses on the accuracy of reporting specific health conditions such as weight and arthritis. For example, Ljungvall, Gerdtham, and Lindblad (2015) find that women with higher education report their weight more accurately, and this differential reporting error leads to an underestimation of the educational disparity in obesity. The generalizability of this is questionable, as it is based on a sample of residents of two municipalities in southern Sweden. In contrast, Gil and Mora (2011) find that the self-report bias in BMI is roughly equal among those with the lowest educational attainment and those with a university degree. Again, this was for a local dataset, in this case of the Catalan population in Spain. Using data from southeastern Netherlands, Mackenbach et al. (1996) compared self-reports of lung disease, heart disease, and diabetes against information from the subjects' general practitioners and found that reporting error tends to bias downward estimates of the educational gradient in such conditions. Butler et al. (1987) found in the U.S. Survey of Disability and Work that those with a high school education (but not those with a college degree) were more likely than high school dropouts to accurately report having arthritis.

In contrast to the literature that examines responses regarding specific health conditions, other research has focused on other types of questions about health. Lindeboom and van Doorslaer (2004) examine responses to general questions about health to which respondent answers can range from "very poor" to "very good." Using data from the Canadian National Population Health Survey, they

\footnotetext{
${ }^{2}$ This paper also relates to the recent literature on the extent of misreporting of weight and its consequences for bias in the prevalence of obesity and in econometric models of the consequences and correlates of obesity (see, e.g., Cullinan and Cawley, 2017; Cawley, Maclean, Hammer, and Wintfeld, 2015; Courtemanche, Pinkston, and Stewart, 2015).
} 
find no evidence that responses differ significantly by education. Bago d'Uva, O'Donnell, and van Doorslaer (2008) focus on how people of different levels of education differentially rate case vignettes that describe levels of functioning within health domains. They examine six health domains (mobility, pain, sleep, breathing, emotional health and cognition) for older individuals in eight European countries. They find that in six countries the more highly educated individuals are generally more critical of a given health state (although in two countries the opposite is true) and that failure to correct for this differential reporting leads to underestimation of health inequalities by education. A related study (Bago d'Uva, van Doorslaer, Lindeboom, and O'Donnell, 2008) corrects self-reported health based on differential rating of hypothetical case vignettes and concludes that better educated people overreport their health in Indonesia and India, but underreport their health in China; as a result, correcting for reporting heterogeneity reduces the educational disparities in health in Indonesia and India but increases them in China. It should be noted that in all of these countries, the highest category of education is relatively low; the equivalent of high school graduate or better. Dowd and Todd (2011) conduct a similar study of differential responding by education to anchoring vignettes in the U.S. Health and Retirement Study.

Other research on reporting error in health has focused on the role of other aspects of socioeconomic status than education. Johnston, Propper, and Shields (2009) primarily examine income gradients in self-reported and measured hypertension in the Health Survey for England, but also find that the better educated are better informed about their health. Two subsequent studies built on this work. Suziedelyte and Johar (2013) estimate socioeconomic gradients in both self-reported and administratively documented major surgeries in New South Wales, Australia, and find that the gradients are unbiased by differential misreporting by education. Mosca et al. (2013) estimate socioeconomic gradients in hypertension and high cholesterol using data from Ireland; odds ratios for 
educational categories were not significantly different when one used self-reports as opposed to objectively measured health, in models that controlled for an extensive set of covariates.

Finally, Banks et al. (2006) document educational gradients in chronic conditions in both selfreported data and biological measures of health in the National Health and Nutrition Examination Surveys (NHANES) 1999-2002 and the Health Survey for England for 2003.

This paper contributes to the literature in the following ways. First, it examines a wide range of health behaviors and conditions: smoking, high blood pressure, high cholesterol, diabetes, and obesity. This is useful because the direction and magnitude of reporting error, and its correlation with education, may differ by health condition and behavior because they vary in the extent to which they are known by the respondent, are socially stigmatized, or are observable by the interviewer. Examining a diverse set of health conditions and behaviors allows us to examine whether there are robust patterns of misreporting by education. Second, this paper verifies subject responses using the results of lab tests, medical examinations, and measurements taken by medical professionals. Third, it studies not only the accuracy of self-reports when compared to objective measures but also the direction of the reporting error (such as false negative or false positive reports) to examine the possibility of social desirability bias in reporting some of the stigmatized behavior or conditions. Fourth, it examines the extent to which education is associated with refusal to take the medical exam, refusal to answer the survey questions, and answering that one doesn't know. Fifth, it examines the extent to which these educational differences in accuracy are explained by differential access to, and utilization of, health care. Finally, it calculates the magnitude of the bias in health disparities across education when using self-reports rather than objective measures; in other words, it examines how the use of self-reports biases estimates of educational disparities in health. This is done using a recent, large, nationally representative dataset for the U.S., which facilitates generalizability. 
We find evidence of differential reporting error across education categories; specifically, those with a college degree are more likely to accurately report behaviors and conditions such as smoking, diabetes, and high blood pressure. We find some evidence consistent with the hypothesis of greater social desirability bias among the better educated; specifically, college graduates are more likely to give false negative reports regarding obesity and high total cholesterol. Only a small percentage of these differences are explained by differential access to, and utilization of, health care.

\section{Data: National Health and Nutrition Examination Survey (NHANES) 1999-2012}

We examine the data from the National Health and Nutrition Examination Survey (NHANES) Continuous for 1999-2012. The NHANES is sponsored by the National Center for Health Statistics of the Centers for Disease Control and Prevention and surveys a nationally representative sample of the U.S. civilian non-institutionalized population that is selected using a complex, stratified, multistage probability cluster sampling design. ${ }^{3}$ NHANES is well-suited for our research question because it is nationally representative and contains both self-reported measures and lab and examination results for an extensive set of health behaviors and conditions, including current smoking status, weight, high blood pressure, cholesterol, and diabetes.

Individuals answer questions about their health behaviors and conditions during the household component, and are tested and examined during a subsequent medical examination component, which takes place in mobile examination centers. $95.5 \%$ of the respondents to the household survey also participate in the examination component of the survey; hemophiliacs and those who received chemotherapy within the last 4 weeks are not included in the lab component.

Our sample is restricted to those who have completed both interview and examination components of NHANES and who are 25 years of age or older and are thus likely to have completed

\footnotetext{
${ }^{3}$ For information on the NHANES sampling frame and data collection methods, see National Center for Health Statistics (2015).
} 
their schooling. We exclude respondents who have missing values for education and those whose home interviews were conducted with a proxy respondent. For regression models of obesity, we also exclude: 1) the 1999-2002 data because during those years the NHANES did not indicate whether the weight or height variables were reported by a proxy; and 2) those who, in any survey year, refused to change into an examination gown when measuring their weight or did not stand up straight or remove their shoes during the measurement of height.

Most questions about health behaviors and conditions are asked in the household interview; the exception is smoking status, which is asked at the mobile examination center. ${ }^{4}$ Individuals are asked whether they have ever been diagnosed with specific conditions; e.g. "Has a doctor or other health professional ever told you that you had (high blood pressure/diabetes/high cholesterol)?" (The full text of question wording is provided in Table 1.) For our purposes, the wording is not ideal because the person may have been diagnosed long ago and the condition resolved. However, we assume that the extent of any such changes does not differ by education.

Smoking status is verified by a urine test for serum cotinine. Cotinine is a metabolite of nicotine, has a half-life of approximately 20 hours, and can be detected for a few days after tobacco use. (The NHANES asks whether the individual used cigarettes or other nicotine products during the past 5 days, which matches the cotinine test much better than asking about smoking in the past 30 days or year.) The level of cotinine in the blood is proportional to the amount of exposure to tobacco smoke (Florescu et al., 2009). The medical literature does not agree on the appropriate cotinine threshold to define a smoker, so we use the two most common thresholds: $15 \mathrm{ng} / \mathrm{ml}$ (Florescu et al., 2009) and 3ng/ml (Benowitz et al., 2009).

\footnotetext{
${ }^{4}$ The fact that smoking is asked just prior to the medical exam may lead respondents to report it more accurately than the questions asked earlier, during the household interview.
} 
Weight is measured by health professionals using a calibrated scale after subjects change into paper examination gowns and remove their shoes. High blood pressure is measured by health professionals. Total cholesterol level is measured from blood specimens. LDL cholesterol level is also measured but only for those who are examined in the morning. Diabetes is assessed two ways: 1) blood glycohemoglobin level; and 2) fasting plasma glucose (FPG) levels. The FPG test is conducted only for those who participated in the morning examination sessions, who were asked in advance to fast; fasting status was verified with a questionnaire before the exam. Table 1 lists, for each health behavior and condition, the relevant NHANES survey question, the relevant NHANES examination or test, and any special restrictions on the sample stemming from the nature of the question or exam.

Based on the results of the medical examinations and tests, we classify individuals as having each condition based on the relevant clinical guidelines. The NIH defines high blood pressure as systolic of 140 or higher or diastolic of 90 or higher (CDC, 2015a). The NHANES survey question about high cholesterol does not distinguish whether the subject was diagnosed with high total cholesterol or high LDL cholesterol, so we examine each; the threshold for high total cholesterol is $240 \mathrm{mg} / \mathrm{dL}$ and that for high LDL cholesterol is $160 \mathrm{mg} / \mathrm{dL}$ (CDC, 2015b). Recall that there are two NHANES tests for diabetes: hemoglobin Alc (HbAIC) and fasting plasma glucose level. A diagnosis of diabetes is associated with $\mathrm{HbA} 1 \mathrm{c}$ of 6.5 or greater or fasting plasma glucose of $126 \mathrm{mg} / \mathrm{dL}$ or greater (CDC, 2015c). Obesity is defined as a body mass index (defined as weight in kilograms divided by height in meters squared) of 30 or higher (US DHHS, 2010).

One possible form of differential social desirability bias is that the better educated are more likely to perceive that the exam will check their self-reported answers, and they may wish to report more accurately to avoid being caught misreporting. This may lead reporting error to vary with education in the NHANES in a way that it would not in a survey that was conducted without an 
accompanying examination. However, the medical examination is not scheduled (and consent not sought) until the end of the home interview (Zipf, 2013), so in general respondents may not be thinking during their interview about a subsequent exam. In addition, the gap in time between the interview and exam (two weeks on average) means that there will be no instantaneous embarrassment from misreporting, and the guarantees of confidentiality of health data mean that the interviewer present for the household interview will not find out the exam results.

For several reasons, we ultimately decided not to report results for sexually transmitted infections (STI). First, the samples were smaller because only a subset of ages (14-49) were tested. Second, the correlations between self-reported and measured values were very low, presumably because STIs may have been contracted (and cured) long before the interview. In contrast, high blood pressure and high cholesterol tend to arise later in life and be more chronic conditions.

\section{Empirical strategy}

We test whether reporting error varies by education by estimating regression models of the following form:

$Y_{i t}=\alpha+\beta$ Education $_{i t}+\gamma X_{i t}+\varepsilon_{i t}$

where $Y_{i t}$ is a measure of reporting error or accuracy for person $\mathrm{i}$ observed at time $\mathrm{t}$. Educationit is a vector of indicator variables for education category (less than high school, some college, and college graduate, with high school graduate as the excluded reference category). $\mathrm{X}_{i t}$ is a vector of indicator variables for respondent characteristics: gender (we pool men and women because we fail to reject the equality of education coefficients across gender), race (non-Hispanic black, Hispanic, and other race, with non-Hispanic white is the omitted reference category), age, and year of interview. We also control for whether the respondent is a U.S. citizen and whether English is the primary language used at home because language and cultural background may affect comprehension of the survey questions. The NHANES records the age in months of the respondent at the interview screener and 
at the examination; we control for the difference between these two ages in our regression models as a means of controlling for the length of time between the self-report and the objective measurement. ${ }^{5}$ However, age at exam is not provided in the 2011-12 NHANES data, so we must drop these years from the regression analysis (although these years are still used in the unconditional analyses). For models of smoking behavior, we also control for the presence of any smokers in the household, because the cotinine test reflects both own smoking and secondhand smoke. We exclude income from the model to allow for differences in income associated with education to be reflected in the correlation of education with the outcomes; we also re-estimated our models controlling for income and found very similar results.

We examine a series of dependent variables that measure the extent of reporting error. The first set measures accuracy regardless of the direction of any reporting error. These dependent variables equal 1 if the measured value matches the self-reported value for a specific health behavior or condition. One legitimate reason that a reported diagnosis might be paired with a negative test result is if the individual is taking medication for the condition; e.g. statins for high cholesterol. The NHANES contains information about prescribed medications, so for those who report being diagnosed with high blood pressure, cholesterol, or diabetes but test negative for it, we code them as accurately reporting the condition if they are currently taking medication for that condition.

The next set of dependent variables takes into account the direction of the error. The dependent variable for false negative reporting is missing for those who are truly negative according to the objective test (because someone who is truly negative is not at risk of giving a false negative report); for those that are truly positive according to the objective test (and thus at risk of giving a

\footnotetext{
5 The NHANES does not provide the exact dates of interview or the exam. In the authors' personal communication with the CDC administrators, we were told that the average gap between the interview and examination is 2 weeks (also see Zipf et al., 2013) and the average gap between the interview screener and the interview is 10 days.
} 
false negative report) the false negative variable equals 1 if the respondent says he does not have the condition and 0 if he says he does have the condition.

Analogously, the dependent variable for false positive reporting is missing for those who are truly positive according to the objective test (because someone who is truly positive is not at risk of giving a false positive report); for those that are truly negative according to the objective test (and thus at risk of giving a false positive report) the false positive variable equals 1 if the respondent says he does have the condition and 0 if he says he does not have the condition.

Dependent variables for false negative and false positive reports are created for each health behavior and condition. The regressions for false negative reporting are particularly informative because they will indicate whether better educated people are over-reporting their health, and thus whether differential reporting error by education explains some of the education gradient in health.

Probit models are estimated, from which we report marginal effects. Regressions are weighted using the Centers for Disease Control and Prevention (CDC) recommended algorithm to construct multi-year survey weights (CDC, 2015d).

Clearly, education and health may affect each other; education may improve health, and individuals may invest in greater education when they perceive that they will be alive for additional periods for the education investment to pay off. However, the goal of this paper is not to estimate the causal effect of education on health ${ }^{6}$, but to determine whether reporting error in health differs by education and whether that explains the educational gradient in health.

\section{Results}

\section{The Educational Gradient in Self-Reported Health}

\footnotetext{
${ }^{6}$ For recent estimates of the causal effect of education on health, see Clark and Royer (2013), McCrary and Royer (2011), de Walque (2007), and Lleras-Muney (2005).
} 
Figure 1 displays the gradient of self-reported health over education in the NHANES, which follows the usual pattern: the better educated report better health. The prevalence of self-reported high blood pressure, high cholesterol, and diabetes decreases monotonically with education. For example, the prevalence of self-reported high blood pressure decreases from $39.0 \%$ among high school dropouts to $25.1 \%$ among college graduates. The prevalence of self-reported diabetes decreases from $17.3 \%$ among high school dropouts to $5.3 \%$ among college graduates.

Self-reported smoking and obesity (based on self-reported weight and height) are negatively correlated with education, but not monotonically. Smoking is actually less common among high school dropouts $(25.2 \%)$ than among high school graduates $(33.7 \%)$, but it is least common among college graduates (13.3\%). Obesity has a similar prevalence among high school dropouts, high school graduates, and those with some college (all of which are in the range of $32.7 \%$ to $34.8 \%$ ) but the prevalence of obesity is much lower among college graduates $(22.9 \%)$. Figure 2 shows that these patterns are relatively similar by gender, with the exception that decreases in unhealthy behaviors and health conditions tend to be less monotonic across education categories for men than women.

\section{Accuracy of Self-Reported Health}

We first examine the accuracy of self-reported health in general, before turning to how that accuracy varies with education. Table 2 lists the unconditional correlations between the self-reported value and the measured value for each behavior and condition. The correlations tend to be high, ranging from .58 for high total cholesterol to over .90 for smoking. Table 3 presents descriptive statistics for the accuracy measures that are the dependent variables in the regression models. On average, most respondents accurately report their health; accuracy ranges from $80.3 \%$ for high total cholesterol to over $95 \%$ for both measures of diabetes and both measures of smoking.

The lower panels of Table 3 provide summary statistics for false negative and false positive reports. False negatives are most common for diabetes (ranging from $21.9 \%$ when the A1c test is used 
to verify to $32.5 \%$ when the plasma glucose test is used) and are rarest for smoking ( $4.2 \%$ for the higher threshold and $6.5 \%$ for the lower threshold). These patterns make sense; smoking is a conscious act and respondents are aware of it, so false negatives should be low. Conversely, high blood pressure and high cholesterol can be asymptomatic, and diabetes may be undiagnosed.

False positives are generally quite low (on the order of 1 to 3 percent) except for high blood pressure (8.2\%) and both measures of high cholesterol (21.4\% for high LDL cholesterol and $20.2 \%$ for high total cholesterol). This may be due to respondents being diagnosed long ago with high blood pressure or high cholesterol, which has since been resolved. Within each condition or behavior, false negative reports tend to be more common than false positive reports; the exception is high cholesterol.

\section{Education and the Accuracy of Self-Reported Health}

We next examine how the accuracy of self-reported health varies with education. Figure 3 shows that, for each measure of health, the likelihood that the self-report matches the objective test is higher for college graduates than for high school dropouts. In most cases, the accuracy rises monotonically with education category.

Table 4 presents marginal effects from probit regressions of the accuracy of self-reported health, regardless of direction of error. The dependent variable equals 1 if the self-report matches the test result and 0 if it does not. The results indicate that college graduates are significantly more likely to accurately report smoking (for both of the two cotinine thresholds), obesity, high blood pressure, and diabetes (by both tests). For example, the college-educated report smoking 0.7 to 1.0 percentage points $(0.7 \%$ to $1.0 \%)$ more accurately (for the cotinine thresholds of 15 and $3 \mathrm{ng} / \mathrm{ml}$ respectively), obesity 1.3 percentage points $(1.4 \%)$ more accurately, high blood pressure 1.6 percentage points (1.8\%) more accurately, and diabetes 0.8 to 1.6 percentage points $(0.8 \%$ to $1.7 \%)$ more accurately (based on the A1c and plasma glucose test respectively), than high school graduates. 
There is very limited evidence of a correlation of education with accuracy at lower levels of educational attainment than college completion. Individuals with some college education are significantly more likely to accurately report smoking (for the lower cotinine threshold only) than high school graduates. Overall, though, there does not seem to be a monotonic relationship between attained schooling and accuracy of self-reported health; instead, there is a substantial nonlinear increase in accuracy with college completion.

Next we examine the association between education and the accuracy of reporting health, taking into consideration the direction of error. Table 5 presents marginal effects from probit models of false negative reporting (i.e. reporting that one does not have the condition when the test indicates that one does). Despite the earlier results showing that college graduates report more accurately overall, college graduates are significantly more likely to give a false negative report for obesity and high total cholesterol. Specifically, among obese individuals, college graduates are 2.9 percentage points $(18.9 \%)$ more likely than high school graduates to report their weight and height in such a way that the resulting BMI is a false negative for obesity. Among respondents with high total cholesterol, college graduates are 3.9 percentage points (20.9\%) more likely than high school graduates to give a false negative report for high total cholesterol. This is striking given both the overall greater accuracy of reports by the college graduates, and the fact that college graduates may have better information about their health, something we examine in greater detail later in this paper.

In two cases lower levels of educational attainment than college graduation are associated with a significantly lower probability of giving a false negative report; those with some college are 1.5 percentage points $(9.7 \%)$ less likely than high school graduates to give a false negative report of smoking, and those with less than high school are 5.7 percentage points (26.0\%) less likely than high school graduates to give a false negative report of diabetes (when validated using the A1c test). 
We next examine the correlates of false positive reporting - i.e. reporting that one has a condition when the test indicates that one does not. Table 6 lists the marginal effects from probit regressions for false positives. College graduates are less likely than high school graduates to submit false positive reports for smoking (lower cotinine threshold only), obesity, high cholesterol (both LDL and total) and diabetes (measured by plasma glucose only). High school dropouts are more likely to provide false positive reports for obesity and total cholesterol, but less likely to provide false positive reports for smoking (both cotinine thresholds) compared to high school graduates.

\section{Implications for the Education Gradient in Health}

We next explore how the differential reporting error by education influences perceptions of the educational gradient in health. There are several comparisons across educational category that could be made; we choose to compare those with a high school diploma or less to those with some college or more. In Table 7 and Figure 4, we show the health discrepancy between these two education categories based on self-reports and objective measurement. For most health conditions and behaviors, the use of self-reports results in underestimates of the true (measured) health disparities across education. For example, the difference in smoking prevalence between the two education categories is 11.3 percentage points when calculated using self-reports, but is 12.2 percentage points when one uses cotinine tests (with a $15 \mathrm{ng} / \mathrm{ml}$ threshold) to determine smoking status. Thus, use of self-reports leads one to underestimate the extent to which the better educated are less likely to smoke by 0.9 percentage points or $7.4 \%$. In some cases, use of self-reports leads to a very large understatement of health differences (e.g. $28 \%$ for diabetes, $25 \%$ for high blood pressure). In contrast, use of self-reports leads to overestimates of the educational disparities in high LDL and high total cholesterol; however, these raw reports have not been adjusted to account for the fact that some people who report having been diagnosed but test negative because they are taking medication for high 
cholesterol. $^{7}$ Across all behaviors and conditions that we examine, use of self-reports results in an overestimate of the true educational gradient in health by an average of $3.035 \%$.

\section{Extension 1: The Role of Health Insurance and Health Care Utilization}

One explanation for why college graduates exhibit greater overall accuracy in self-reported health is that they have greater access to, and utilization of, health care. This could result from their higher income or because of a greater demand for health (Grossman, 1972), and this increased access and utilization may result in them being more likely to have been diagnosed with conditions, conditional on having them. In the literature on measurement of health disparities, this is known as diagnosis bias (see, e.g. Burgard and Chen, 2014). This is not relevant for smoking, for which no diagnosis from a doctor is needed, but may be very relevant for asymptomatic conditions such as high blood pressure or cholesterol. Subjects with greater health care utilization may even have better information about their weight, which can be measured at home but is routinely measured at doctor visits.

We investigate whether health insurance and health care utilization explain the correlation between education and self-report accuracy by re-estimating the models of the paper adding controls for health insurance coverage and type (private insurance, Medicare, Medicaid/SCHIP, with uninsured as the omitted reference category $)^{8}$ and the number of doctor visits ${ }^{9}$ and an indicator variable for whether the respondent was hospitalized in the past year.

Table 8 presents the marginal effects from probit regressions of accuracy of self-reported health, regardless of the direction of error. The results follow the same pattern as in Table 4 but the point estimates tend to be slightly smaller. Even controlling for health insurance and health care

\footnotetext{
${ }^{7}$ Likewise, the reports for high blood pressure and diabetes have also not been adjusted to account for use of medications for those conditions.

${ }^{8}$ We also control for indicator variables for missing values of health insurance variables.

${ }^{9}$ The NHANES records categories, not the exact number, of doctor visits and inpatient stays. We control for a full set of indicator variables for categories of use, with 0 the omitted reference category.
} 
utilization, college educated individuals report their smoking status 0.6 percentage points $(0.6 \%)$ and 0.9 percentage points $(0.9 \%)$ more accurately (for the cotinine thresholds of 15 and $3 \mathrm{ng} / \mathrm{ml}$ respectively), report obesity 1.1 percentage points $(1.2 \%)$ more accurately, and report diabetes roughly 0.7 percentage points $(0.7 \%)$ and 1.4 percentage points $(1.5 \%)$ more accurately (based on A1C and plasma glucose test respectively) than high school graduates. The point estimate suggests that college graduates report high blood pressure more accurately as well, but it is no longer statistically significant. On the whole, the finding that college graduates report their health more accurately is robust to inclusion of controls for health insurance and health care utilization.

We also examine how controlling for health insurance and health care utilization affects estimates of the association of education with the direction of reporting error. Table 9 presents the marginal effects from probit models of false negative reporting and Table 10 presents the marginal effects from probit models of false positive reporting. The results for college graduates are very robust; even controlling for access and utilization, college graduates are significantly more likely to give false negative reports for obesity and total cholesterol and less likely to give false positive reports for smoking (lower cotinine threshold only), obesity, high cholesterol (both LDL and total) and diabetes (plasma glucose test only). Those with some college remain less likely to give false negative reports

of smoking (both cotinine thresholds), and high school dropouts remain less likely to give false positive reports of smoking (both cotinine thresholds) and more likely to give false positive reports of obesity. In summary, differences in access and utilization do not explain these educational disparities in misreporting of health.

\section{Extension 2: Role of Refusals and Don't Knows}

Measurement error can also arise from subjects refusing to participate in the examination, refusing to answer the survey question or saying that they don't know. As an extension, we test 
whether the probability of participating in the examination and the probability of giving such responses varies with subject education.

Table 11 lists the percent of the sample that refused to answer each question or said they didn't know the answer. The main conclusion from the table is that very few respondents refuse to answer or say they don't know the answers to these health questions. For almost all questions the refusal rate is 0 or very close to 0 ; the exception is weight $(0.03 \%$ refusals $)$. We estimate probit models of refusing to answer the weight question and find that education is not significantly correlated with the probability of refusal (see Table 12).

The percentages of respondents who say they don't know are greater than those for refusals, but still very small. The highest percentages saying they don't know are for weight $(0.94 \%)$, height (1.41\%) and high cholesterol (0.75\%). Probit models for responding don't know, which are listed in Table 12, indicate that those with some college and college graduates are 0.3 percentage points (46.2\%) less likely than high school graduates to say they don't know whether they were diagnosed with high cholesterol. In addition, high school dropouts are 0.3 percentage points $(60 \%)$ more likely, and college graduates are 0.2 percentage points (40) less likely, to say they don't know their weight, relative to high school graduates. High school dropouts are also more likely to report that they do not know their height by 0.2 percentage points $(33.3 \%)$ than high school graduates. For both height and weight, high school dropouts are more likely to report that they do not know even when we control for health insurance status and health care utilization variables.

A very high percentage $(95.5 \%)$ of the NHANES respondents participate in both interview and examination parts of the survey, but it is possible that better educated individuals are more likely to refuse to complete the examination due to social desirability bias or a higher opportunity cost of time. To test this, we estimate probit models of refusing to complete the examination as a function of education and other regressors as in the earlier model. Table 12 shows that college graduates are 
0.9 percentage points $(17.3 \%)$ more likely than high school graduates to refuse the examination. This could reflect greater social desirability bias or a higher opportunity cost of time.

\section{Robustness Check 1: Role of Recent Measurements}

One possible explanation for why college graduates tend to report more accurately is that they tend to have more recent (and thus more accurate) information about their health. In this section, we investigate that possibility.

In certain years, the NHANES also contains information about whether respondents had a blood pressure reading by a doctor or health professional in the past year (1999-2004), whether the respondent took their own blood pressure reading at home in the past year (2009-12), and whether the respondent had their cholesterol checked in the past year (1999-2012). To investigate whether better educated individuals are more likely to have recent information, we estimate models in which each of those variables is the dependent variable, and regress it on education as well as the other demographic information.

The results (in Table 13) indicate that high school dropouts are less likely to have had their blood pressure checked by a doctor in the past year, and less likely to have checked their own blood pressure at home in the past year. College educated individuals are more likely to have had their blood pressure checked than high school graduates in the past year. This could suggest that college graduates are more likely to visit the doctor's office to check blood pressure, checkup or for other conditions. Once we control for, health care utilization and insurance status, education is not significantly correlated with likelihood of having a blood pressure reading by a doctor within the past year. However, after taking into account respondent's health care utilization and insurance status, college educated individuals are less likely to have blood pressure reading at home within the year. Otherwise, education is not significantly correlated with the variable reflecting recent information on cholesterol levels. 
When we add to the models of accuracy, false negative reports, and false positive reports controls for whether the respondent's blood pressure was measured in the past year by a doctor (Table 14), we find that it is associated with a lower probability of false negative reports and a higher probability of false positive reports. The coefficient on the indicator variable for college graduates indicates that college graduates remain more likely to report accurately overall, are more likely to give a false negative report for high blood pressure, but also less likely to give a false positive report for high blood pressure. Once we control for health insurance and health care utilization, education is not significantly related to false negative and false positive reporting of high blood pressure but individuals with some college education remain significantly more likely to accurately report high blood pressure.

When we instead control for whether the respondent has taken their blood pressure at home in the past year (Table 15), we find that college graduates remain significantly more likely to give an accurate report and significantly less likely to give a false positive report, but they are no longer significantly more likely to give a false negative report, although this may be due to the smaller sample size because this question was only asked in a subset of years; the point estimate for college graduates remains relatively large (4.3 percentage points or $20 \%)$. Results for false positive reporting holds true when we control for health insurance and health care utilization status.

The earlier findings concerning high cholesterol are robust to the control for whether the respondent had their cholesterol checked in the past year; college graduation remains significantly associated with a higher probability of a false negative report of high total cholesterol and a lower probability of a false positive report of high LDL cholesterol or high total cholesterol. These results are available upon request.

Overall, we find little evidence that the tendency of college graduates to report their health more accurately is due to them having more recent information. 


\section{Robustness Check 2: Controls for Family History of Disease}

Another possibility is that people in different educational categories have a differing probability of having a family member with the disease, and those who have family members with the disease either have better health information or are more likely to recall their own condition.

We are able to investigate this possibility, but only for diabetes and high blood pressure. The NHANES asks whether the respondent had any biological relatives (including grandparents, parents, or siblings) who had been diagnosed with diabetes; this was asked in all years (although grandparents were only included in the list of relevant relatives for 1999-2004). A similar question was asked about high blood pressure but it was phrased as "high blood pressure or stroke before the age of 50" so it is not specific to high blood pressure, and it was only asked for a subset of years (1999-2004) (Appendix Table 14 for further details).

As a robustness check, we re-estimate the models for diabetes controlling for whether the respondent had any biological relatives who were diabetic. The results, in Table 16, are very consistent with the earlier results: college graduates are more likely to provide accurate reports of diabetes (for both the A1c and plasma glucose tests) and are less likely to give false positive reports of diabetes (plasma glucose test only) (Table 16).

We also re-estimate the models for high blood pressure controlling for whether there was a family history of high blood pressure or stroke. Because the family history of high blood pressure was asked only in a subset of years, we estimate the model using this new sample both including and excluding the family history variable. The results are virtually unchanged by controlling for family history; college graduates remain more likely to report high blood pressure accurately and are less likely to give a false positive for high blood pressure. These results are available upon request.

As another related robustness check, we add to the models regarding high cholesterol a control for whether someone in the respondent's family had a heart condition; adding this control has little 
impact on the results (Table 17): college graduates continue to be more likely to give false negative reports for high total cholesterol and less likely to give false positive reports for high LDL or high total cholesterol. Overall, the results of these additional models suggest that the original results are not due to differential likelihood across education of having a family member with that condition.

\section{Additional Robustness Checks}

We conducted a number of other robustness checks. For example, we investigated the possible role of depression, which may vary across education groups and also affect the accuracy of recall or reporting. Although questions related to depression are asked annually of NHANES respondents, the question is only asked for half-sample of examination participants of ages 20 to 39 for the earlier waves (1999-2004). From 2005, participants from age 18 and older responded to the questions on depression. Thus, when we control for depression, sample sizes are reduced. This is particularly an issue for models of false negatives, because it is estimated using only people verified as having the condition (only they are at risk of giving a false negative report). Despite the smaller sample size, we continue to find that college graduates remain significantly more likely to give accurate reports of smoking (lower cotinine threshold only) and diabetes (A1c test only), and less likely to give false positive reports of obesity (see Appendix Tables 1, 2, and 3).

Over time in the U.S., cigarette smoking has become far less common and the prevalence of obesity has risen dramatically. As a result, the stigma associated with smoking may have risen and that associated with obesity may have fallen, and this may result in changes over time in social desirability bias and the extent of false negative reports by education. The years covered by our data (1999-2012) preclude us from examining long-run trends, but to investigate this possibility we create an indicator variable for the second half of the panel (2005-2012) and control for it as well as its interaction with each education category. The interactions of education and time do not provide evidence of trends in misreporting by education categories, and some of the main educational effects 
are statistically significant (e.g. college graduates are more likely to accurately report smoking and high blood pressure, and are less likely to give false positive reports of smoking and high total cholesterol) (see Appendix Table 4, 5, and 6).

For smoking, those who are occasional smokers or very light smokers who do not use cigarettes regularly may less likely to report that they are smokers. The NHANES provides information on the number of cigarettes smoked on the day that respondents smoked during the past 30 days. We defined "light smokers" as those smoking less than 5 cigarette per day during the past month, following the definition of Schane, Ling and Glantz (2010). We re-estimate the same probit models of accurate, false negative and false positive reporting of smoking excluding the respondents who reported smoking fewer than 5 cigarettes in a month. The results for accurate, false negative, and false positive reporting of smoking are very similar to the baseline results for both cotinine thresholds and some coefficients have a larger magnitude in these robustness regressions (Appendix Table 7).

Another questionnaire in the NHANES can serve as a proxy for defining an intermittent or occasional smoker. The question asks whether the respondents smoke cigarettes now with 3 response categories: every day, some days, not at all (very few choose don't know or refuse to answer). Appendix Table 8 shows the re-estimated probit models of accurate, false negative and false positive reporting of smoking excluding the sample who reported they smoke "some days". For both of these robustness regressions excluding light or occasional smokers, we find similar results as in the baseline specification: college graduates are more likely to provide accurate reports of smoking (both thresholds) and are less likely to provide false positive reports of smoking compared to high school graduates (Appendix Tables 7 and 8).

We also sought to investigate whether the educational disparities in accuracy could be due to the better educated being diagnosed earlier in life with their conditions. The NHANES asks about age 
of diagnosis for diabetes and high blood pressure, but using these variables has two drawbacks: 1) it exists only for those who reported having the condition, so one cannot estimate models of false negative reports (those who said they were never diagnosed were not asked age of diagnosis) or overall accuracy (because false negatives are omitted); and 2) the question for age of first diagnosis of high blood pressure was only asked in the later waves of the NHANES (2007-2010), which considerably reduces the sample sizes. When we estimate models of whether a positive self-report of diabetes was verified by the test (that is, whether the report is a true positive versus false positive), we find that college graduates are less likely to have given an accurate report whether or not one controls for self-reported age of first diagnosis. We find similar results for high blood pressure: among those who report having high blood pressure, college graduates are less likely to have given an accurate report (true positive report) whether or not one controls for self-reported age of first diagnosis (Appendix Table 9). This is consistent with the better-educated experiencing greater social desirability bias.

As a robustness check, we re-estimate our models for high cholesterol and diabetes using only the sample of respondents who had non-missing values for both tests for each condition. To clarify, only those who had NHANES medical exams in the morning (not those in the afternoon) were administered a test for high LDL cholesterol and the fasting plasma glucose test. Tests for high total cholesterol and A1c were administered in both the morning and afternoon exams. To better compare results across the two tests, we limit the sample to those with non-missing values for both tests for a given condition. For high cholesterol, the point estimates remain similar to the main results, although some are no longer statistically significant given the smaller samples (Appendix Table 10). College graduates remain less likely to give false positive reports of high LDL cholesterol. For diabetes, the results are quite robust: college graduates provide significantly more accurate reports and are significantly less likely to give false positive reports of diabetes (Appendix Table 11). 
One issue with false negative reporting is that it can be observed only for respondents who test positive for the condition; we cannot observe whether a truly negative person would have misreported if they were truly positive. Johnston et al. (2009) choose to estimate a censored model for this reason. As a robustness check, we estimate a model of false negative reports for the entire sample (not just those who test positive) using STATA's heckprobit command. As before, we find that the college graduates are significantly more likely to give false negative reports of high total cholesterol, but the censored model also finds that college graduates are significantly more likely to give false negative reports of smoking (of roughly 1.2 percentage points or 18.5\%) (Appendix Table 12).

Finally, we estimate seemingly unrelated regression models of accuracy for all conditions and behaviors, using the sample of respondents who had valid data for each regression. These results too, indicate that college graduates report their health more accurately; this is true for smoking (both cotinine levels), obesity, and diabetes (both tests) (Appendix Table 13).

\section{Conclusion}

This paper improves our understanding of one of the most robust findings in health economics the positive correlation between education and health. It does so by testing a novel hypothesis for the positive correlation between education and health: differential reporting error by education. We hypothesized that the better educated may be less likely to report socially stigmatized health behaviors like smoking and excess weight, with the consequence of exaggerating true differences in health across education categories. We do in fact find that college graduates are more likely to give false negative reports for obesity and high total cholesterol. However, they are also significantly less likely to provide false positive reports for smoking, obesity, high cholesterol, and diabetes. Given that there are more truly negative individuals at reduced risk of giving a false positive report than there are truly 
positive individuals at higher risk of giving a false negative report, college graduates tend to report significantly more accurately overall (for smoking, obesity, high blood pressure, and diabetes).

It is striking that this difference in accuracy is found for conscious acts (smoking), characteristics that are easily measured at home (weight), and asymptomatic conditions that would need to be diagnosed by a doctor (high blood pressure). It is also found for conditions that are partially observable to the interviewer (weight) as well as those that are unobservable by the interviewer (high blood pressure, diabetes). The consistency of this pattern across conditions and behaviors suggests that the mechanisms may be substantially cognitive - that college graduates are better able to comprehend the questions and give accurate answers. The increased likelihood of false negative reporting by college graduates for obesity and high total cholesterol is consistent with social desirability bias being greater for college graduates.

The overall greater accuracy exhibited by college graduates does not appear to be due to them having greater access to and utilization of health care; the finding is robust to controlling for whether the respondent has health insurance (and its type), number of doctor visits and whether they have been hospitalized in the past year.

Likewise, we do not find evidence that the pattern is due to college graduates having more recent information; controlling for whether respondents had a blood pressure reading by a doctor in the past year or measured their own blood pressure at home in the past year had little effect on the result that college graduates more accurately report having high blood pressure. This is consistent with earlier research that finds that differential information explains little of the educational gradient in health (se, e.g. Cutler and Lleras-Muney, 2010). Controlling for family history of the disease likewise had little impact on the finding that college graduates significantly more accurately report blood pressure and diabetes. 
One possible reason that the better educated may report more accurately is that they better understand the questions. The NHANES asks respondents whether they have ever been diagnosed by a doctor or health professional with the condition. It is possible that less-educated individuals misinterpret the question as whether they currently have the condition and report no if they are on medication to control the condition. However, to address that specific possibility we do not code a response as a false negative if the person reports that they do not have the condition when the objective test says that they do, as long as they also report taking medication for the condition (this is relevant for high blood pressure, high cholesterol, and diabetes). Although that particular cognitive error cannot explain the patterns we find, it remains possible that college graduates may be more likely to understand the questions or be more likely to give a precisely accurate response.

Although we find some evidence consistent with greater social desirability bias among the bettereducated (specifically, that college graduates are more likely to give false negative responses for obesity and high total cholesterol), it is possible that the better educated experience greater social desirability bias for all conditions and behaviors, but that in most cases it is outweighed by increased accuracy from cognitive factors. All we observe is the net of these various possible influences on accuracy, false negatives, and false positives, we cannot distinguish the contribution to each from each source of misreporting.

Although we robustly find that college graduates report their health more accurately, we do not find evidence of a monotonic increase in accuracy with completed education. Instead, accuracy seems to be statistically indistinguishable between those with less than high school educations, high school but no college, and some college. Although with these data we cannot investigate why accuracy is higher for college graduates but not for those with some college (relative to high school graduates), it is consistent with the literature in education which finds that the labor market return to individual years of schooling is small relative to the substantial "sheepskin effects" of college graduation (e.g. 
Jaeger and Page, 1996). A direction for future research is to estimate the causal relationship between education and differential reporting error of health behaviors and conditions; that is, does increasing education have the causal effect of increasing one's accuracy in reporting health or answering surveys generally?

This paper complements the literature on reporting error in health (e.g. Johnston et al., 2009; Bago d'Uva et al., 2008; Lindeboom et al., 2004) by demonstrating that differential reporting error by education can bias estimates of the educational gradient in health, using data on widely varied health conditions and behaviors for a large, nationally representative dataset. It also finds evidence of increased social desirability bias among the high-educated for certain conditions (i.e. that college graduates are more likely to provide false negative reports of obesity and high cholesterol).

A limitation of our study is that respondents are asked whether they have ever been diagnosed with specific conditions, whereas the tests indicate whether respondents currently have the condition; subjects may have been diagnosed long ago, the condition resolved, and the respondent is no longer on medication. We assume that any such discrepancies do not differ by education, but it is possible that they do, for example due to educational differences in management of chronic disease. However, such discrepancies would bias the results towards finding that the less educated reported more accurately (because they are more likely to still have the chronic disease), whereas our results indicate the opposite. Thus, any such bias implies that the better educated report their health even more accurately relative to the less educated than our results suggest.

The extent of misreporting of health underscores the importance of collecting objective measures of health behaviors and conditions in surveys. To clarify, the problem lies not with researchers - when both measurements and self-reports are available, researchers tend to use the measurements - but with datasets, which frequently include only self-reports. Data producers should 
carefully consider the cost-effectiveness of including measurements of health and objective verification of health behaviors and conditions in their datasets.

Data producers can also take steps to maximize the accuracy of responses to interview questions on health. This could take the form of selecting the mode of survey to encourage more accurate reporting (see, e.g., Brener et al., 2003) or offering rewards for accurate reporting for a subset of the sample that has their answers verified (see, e.g., Philipson, 1997, 2001). Such strategies may reduce the average reporting error, even if not the educational differences in it. 


\section{Works Cited}

Bago d'Uva, T., O’Donnell, O., \& van Doorslaer, E. 2008. Differential health reporting by education level and its impact on the measurement of health inequalities among older Europeans. International Journal of Epidemiology, 37, 1375e1383.

Bago d'Uva, T., Van Doorslaer, E., Lindeboom, M., \& O'Donnell, O. (2008). Does reporting heterogeneity bias the measurement of health disparities? Health Economics, 17(3), 351-375.

Banks, J., Marmot, M., Oldfield, Z. \& Smith, J.P. 2006. Disease and Disadvantage in the United States and in England. JAMA, 295: 2037-2045.

Benowitz, N. L., Bernert, J. T., Caraballo, R. S., Holiday, D. B., \& Wang, J. (2009). Optimal serum cotinine levels for distinguishing cigarette smokers and nonsmokers within different racial/ethnic groups in the united states between 1999 and 2004. American Journal of Epidemiology, 169(2), 236-248.

Benowitz, N. L., Dains, K. M., Dempsey, D., Herrera, B., Yu, L., \& Jacob, 3., Peyton. (2009). Urine nicotine metabolite concentrations in relation to plasma cotinine during low-level nicotine exposure. Nicotine \& Tobacco Research : Official Journal of the Society for Research on Nicotine and Tobacco, 11(8), 954-960.

Brener, N. D., Billy, J. O. G., \& Grady, W. R. (2003). "Assessment of factors affecting the validity of self-reported health-risk behavior among adolescents: Evidence from the scientific literature." Journal of Adolescent Health, 33, 436-457.

Burgard, S. A., \& Chen, P. V. (2014). Challenges of health measurement in studies of health disparities. Social Science \& Medicine (1982), 106, 143-150.

Butler, J. S., Burkhauser, R. V., Mitchell, J. M., \& Pincus, T. P. (1987). Measurement error in selfreported health variables. The Review of Economics and Statistics, 69(4), 644-650.

Cawley, J., Maclean, J.C., Hammer, M., Wintfeld, N. 2015. "Reporting Error in Weight and its Implications for Estimates of the Economic Consequences of Obesity." Economics and Human Biology, 19: 27-44.

Centers for Disease Control and Prevention (CDC), 2015.

http://www.cdc.gov/nchs/tutorials/nhanes/SurveyDesign/Weighting/intro.htm Accessed June 2, 2015.

Centers for Disease Control and Prevention (CDC), 2015a.

http://www.cdc.gov/bloodpressure/measure.htm Accessed June 3, 2015

Centers for Disease Control and Prevention (CDC), $2015 \mathrm{~b}$.

http://www.cdc.gov/nchs/data/databriefs/db92.pdf Accessed June 3, 2015

Centers for Disease Control and Prevention (CDC), $2015 \mathrm{c}$.

http://www.cdc.gov/diabetes/pdfs/data/2014-report-national-diabetes-statistics-report-datasources.pdf Accessed June 3, 2015

Centers for Disease Control and Prevention (CDC). 2015d. National Center for Health Statistics (NCHS). National Health and Nutrition Examination Survey Questionnaire (or Examination Protocol, or Laboratory Protocol). Hyattsville, MD: U.S. Department of Health and Human Services, Centers for Disease Control and Prevention, http://www.cdc.gov/nchs/data/nhanes/pe.pdf Accessed June 3, 2015.

Clark, D., \& Royer, H. (2013). The effect of education on adult mortality and health: Evidence from britain. The American Economic Review, 103(6), 2087-2120.

Connor Gorber S, Tremblay M, Moher D, Gorber B. 2007. A comparison of direct vs. self-report measures for assessing height, weight and body mass index: a systematic review. Obesity Reviews, 8: 307-326.

Courtemanche, C., Pinkston, J.C., Stewart, J. 2015. "Adjusting body mass for measurement error with invalid validation data," Economics \& Human Biology, 19: 275-293. 
Cullinan, J., J. Cawley. 2017. "Parental Misclassification of Child Overweight/Obese Status: The Role of Parental Education and Parental Weight Status." Economics \& Human Biology, 24: 92103.

Cutler, D. M., \& Lleras-Muney, A. (2010). Understanding differences in health behaviors by education. Journal of Health Economics, 29(1), 1-28.

Cutler, D. M., Huang, W., \& Lleras-Muney, A. (2015). When does education matter? The protective effect of education for cohorts graduating in bad times. Social Science \& Medicine (1982), 127, 63-73. doi:10.1016/j.socscimed.2014.07.056

Dowd, Jennifer Beam, and Megan Todd. 2011. "Does Self-reported Health Bias the Measurement of Health Inequalities in U.S. Adults? Evidence Using Anchoring Vignettes From the Health and Retirement Study." J Gerontol B Psychol Sci Soc Sci, 66B(4): 478-489.

Flood, V., Webb, K., Lazarus, R., \& Pang, G.. (2000). Use of self-report to monitor overweight and obesity in populations: Some issues for consideration. Australian and New Zealand Journal of Public Health, 24(1), 96-99.

Florescu, A., Ferrence, R., Einarson, T., Selby, P., Soldin, O., \& Koren, G. (2009). Methods for quantification of exposure to cigarette smoking and environmental tobacco smoke: Focus on developmental toxicology. Therapeutic Drug Monitoring, 31(1), 14-30.

Gil, J., Mora, T.: 2011. The determinants of misreporting weight and height: the role of social norms. Econ. Hum. Biol. 9: 78-91.

Grossman, M. (1972). On the concept of health capital and the demand for health. Journal of Political Economy, 80(2), 223-255.

Grossman, M. (1982). The demand for health after a decade. Journal of Health Economics, 1(1), 1-3.

Grossman, M., \& Kaestner, R. (1997). Effects of education on health. In J. Behrman, \& N. Stacey (Eds.), The social benefits of education (pp. 69-123). Ann Arbor: University of Michigan Press.

Grossman, M. (2008). The relationship between health and schooling. Eastern Economic Journal, 34(3), 281-292.

Jaeger, David A. and Marianne E. Page. 1996. "Degrees Matter: New Evidence on Sheepskin Effects in the Returns to Education." Review of Economics and Statistics, 78(4): 733-740.

Johar, M., \& Suziedelyte, A. (2013). Can you trust survey responses? Evidence using objective health measures. Economics Letters, 121(2), 163-166.

Johnston, D. W., Propper, C., \& Shields, M. A. (2009). Comparing subjective and objective measures of health: Evidence from hypertension for the income/health gradient. Journal of Health Economics, 28(3), 540-552.

Kenkel, D. S. (1991). Health behavior, health knowledge, and schooling. The Journal of Political Economy, 99(2), 287-305.

Lindeboom, M., van Doorslaer, E., 2004. Cut point shifts and index shift in self-reported health. Journal of Health Economics 23, 1083-1099.

Lleras-Muney, A. (2005). The relationship between education and adult mortality in the United States. The Review of Economic Studies, 72(1), 189-221.

Ljungvall, Asa, Ulf G. Gerdtham, and Ulf Lindblad. 2015. "Misreporting and misclassification: implications for socioeconomic disparities in body-mass index and obesity." European Journal of Health Economics, 16: 5-20.

Mackenbach, J. P., Looman, C. W., \& van der Meer, J. B. 1996. Differences in the misreporting of chronic conditions, by level of education: The effect on inequalities in prevalence rates. American Journal of Public Health, 86(5), 706-711.

McCrary, J., \& Royer, H. (2011). The effect of female education on fertility and infant health: Evidence from school entry policies using exact date of birth. American Economic Review, 101(1), 158-195. 
Mosca, I., Ni Bhuachalla, B., \& Kenny, R. A. (2013). a new look at the socio-economic health gradient: Objective and subjective measures of cardiovascular health. Age and Ageing, 42(2), S71(1).

National Center for Health Statistics. 2015. NHANES 2011-2012. http://wwwn.cdc.gov/nchs/nhanes/search/nhanes11_12.aspx Accessed January 22, 2015.

Philipson, Tomas, 1997. "Data Markets and the Production of Surveys," Review of Economic Studies, 64(1): 47-72.

Philipson, T. (2001), "Data markets, Missing Data, and Incentive Contracting.", Econometrica, 69(4):,1099-1111.

Royer, H., \& McCrary, J. (2011). The effect of female education on fertility and infant health: Evidence from school entry policies using exact date of birth. The American Economic Review, 101(1), 158-195.

Schane, R. E., Ling, P. M., \& Glantz, S. A. (2010). Health Effects of Light and Intermittent Smoking: A Review. Circulation, 121(13), 1518-1522.

U.S. Department of Health and Human Services. 2010. The Surgeon General's Vision for a Healthy and Fit Nation. Rockville, MD: U.S. Department of Health and Human Services, Office of the Surgeon General.

Zipf G, Chiappa M, Porter KS, et al. 2013. National Health and Nutrition Examination Survey: Plan and operations, 1999-2010. National Center for Health Statistics. Vital Health Stat 1(56). 
Figure 1. Prevalence (\%) of Self-Reported Health Behaviors and Conditions by Education

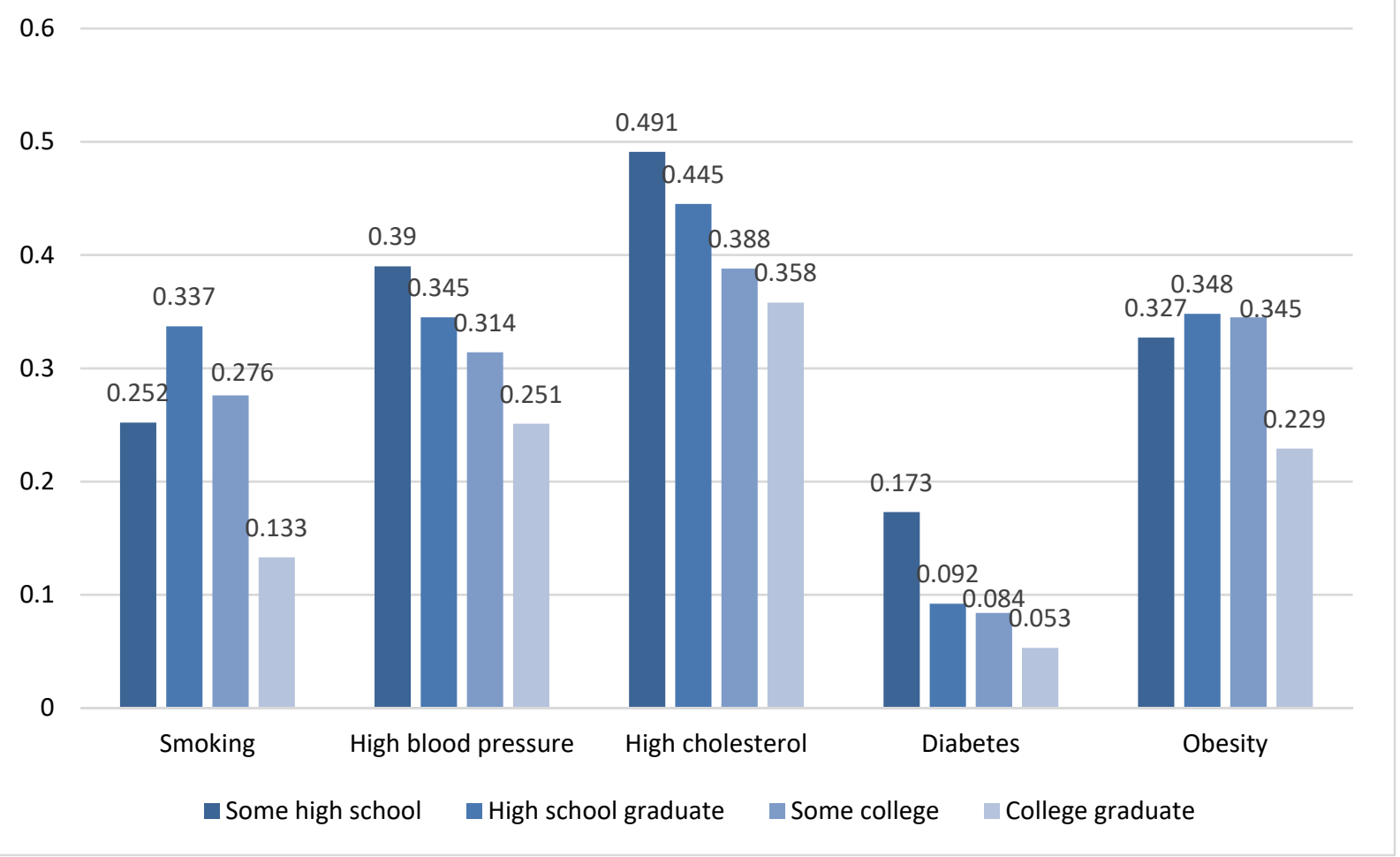

Data: pooled Continuous NHANES 1999-2012 data

Note: Sample includes those who are 25 or older, completed both interview and examination components, and excludes those who have missing values for education and those who reported any of the survey data by a proxy respondent. For obesity, we exclude the data before 2003 cycle because it is uncertain whether any of the weight or height variables are reported by a proxy. Also, we exclude individuals who refused to change into examination gown or did not stand up straight or wore shoes when examining weight and height. 
Figure 2. Prevalence (\%) of Self-Reported Health Behaviors and Conditions by Education and Gender

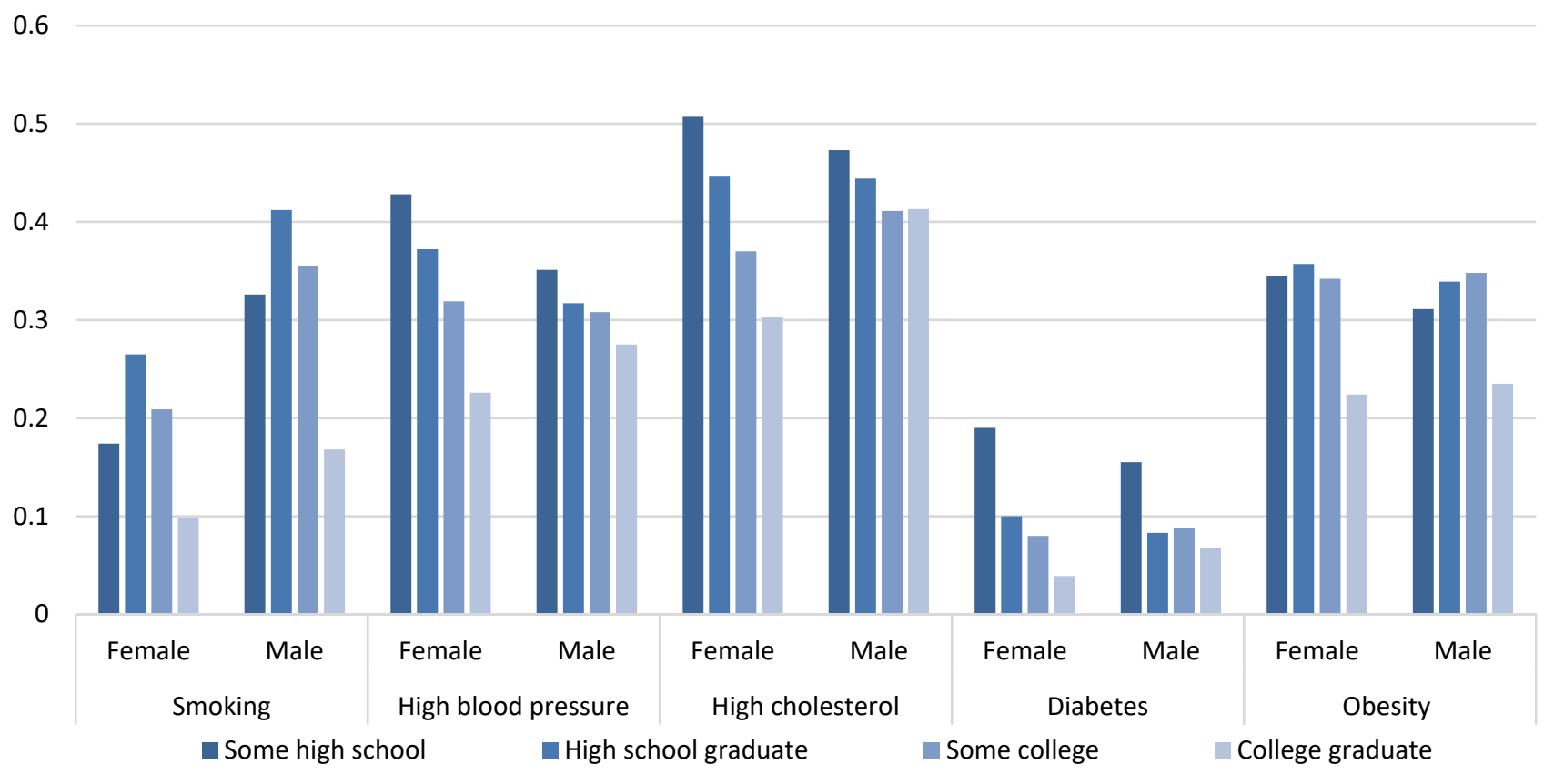

Data: pooled Continuous NHANES 1999-2012 data

Note: Sample includes those who are 25 or older, completed both interview and examination components, and excludes those who have missing values for education and those who reported any of the survey data by a proxy respondent. For obesity, we exclude the data before 2003 cycle because it is uncertain whether any of the weight or height variables are reported by a proxy. Also, we exclude individuals who are pregnant, who refused to change into examination gown or did not stand up straight or wore shoes when examining weight and height. 
Figure 3. Accuracy (\%) of Self-Reported Health Behaviors and Conditions by Education

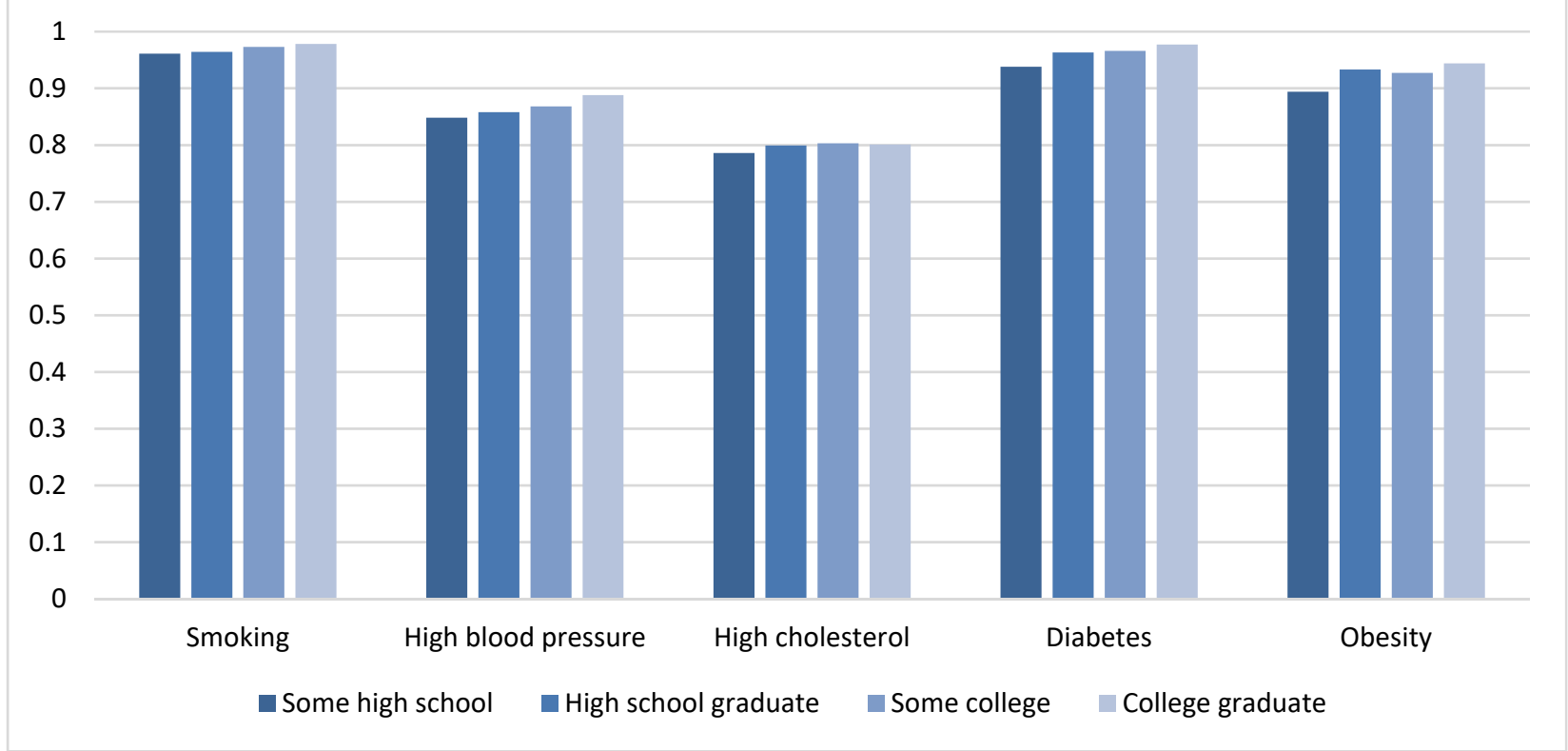

Data: continuous NHANES 1999-2012 (pooled).

Note: Sample includes those who are 25 or older, completed both interview and examination components, and excludes those who have missing values for education and those who reported any of the survey data by a proxy respondent. For obesity, we exclude the data before 2003 cycle because it is uncertain whether any of the weight or height variables are reported by a proxy. Also, we exclude individuals who are pregnant, who refused to change into examination gown or did not stand up straight or wore shoes when examining weight and height. 
Figure 4. Health Disparities across Education Groups

(comparing high school graduate or less vs. some college or college graduates)

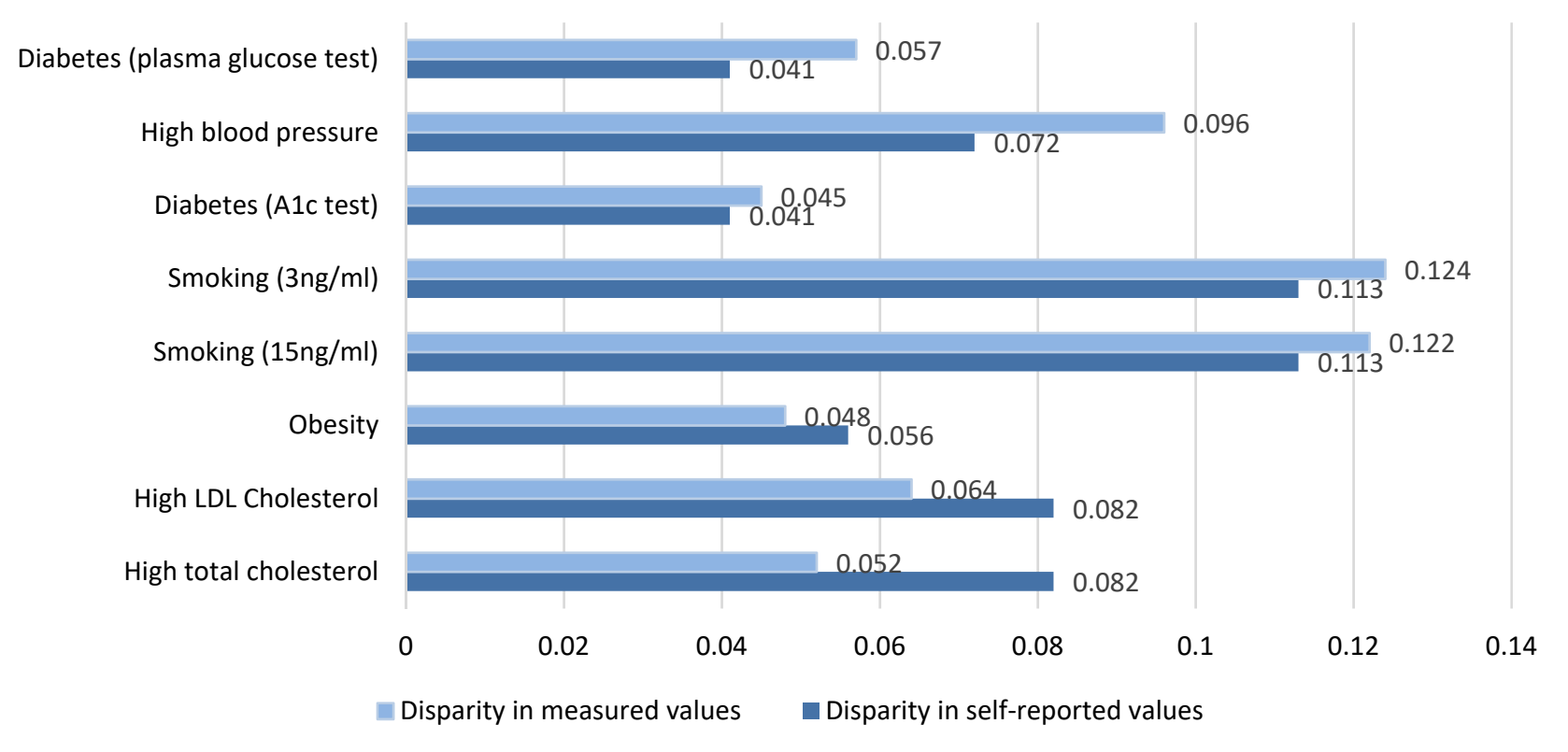

Data: continuous NHANES 1999-2012 (pooled).

Note: Sample includes those who are 25 or older, completed both interview and examination components, and excludes those who have missing values for education and those who reported any of the survey data by a proxy respondent. For obesity, we exclude the data before 2003 cycle because it is uncertain whether any of the weight or height variables are reported by a proxy. Also, we exclude individuals who are pregnant, who refused to change into examination gown or did not stand up straight or wore shoes when examining weight and height. 
Table 1. Information on Self-Reported and Objectively Measured Health Data

\begin{tabular}{|c|c|c|c|}
\hline $\begin{array}{c}\text { Health } \\
\text { Behavior/Condition }\end{array}$ & Survey Question & Objective Tests & $\begin{array}{c}\text { Notes (eligible sample, exclusion } \\
\text { criteria etc.) }\end{array}$ \\
\hline Smoking & $\begin{array}{l}\text { During the past } 5 \text { days, did } \\
\text { [respondent] use any product } \\
\text { containing nicotine including } \\
\text { cigarettes, pipes, cigars, chewing } \\
\text { tobacco, snuff, nicotine patches, } \\
\text { nicotine gum, or any other product } \\
\text { containing nicotine? }\end{array}$ & $\begin{array}{l}\text { Measured by serum cotinine levels in } \\
\text { urine tests. We examine two cotinine } \\
\text { cutoffs to define smoking status: } \\
15 \mathrm{ng} / \mathrm{ml}, 3 \mathrm{ng} / \mathrm{ml} \text { respectively }\end{array}$ & $\begin{array}{l}\text { Question on recent tobacco use } \\
\text { asked at the mobile examination } \\
\text { center where various lab tests and } \\
\text { examinations are conducted }\end{array}$ \\
\hline Weight and height & $\begin{array}{l}\text { How much do you weigh without } \\
\text { clothes or shoes (lbs)? } \\
\text { How tall are you without shoes } \\
\text { (inches)? }\end{array}$ & $\begin{array}{l}\text { Measured by health professionals } \\
\text { using calibrated scale, tape measure }\end{array}$ & $\begin{array}{l}\text { We examine waves after } 2001 \\
\text { because earlier waves did not } \\
\text { indicate whether proxies responded } \\
\text { to the questionnaires } \\
\text { We exclude respondents who were } \\
\text { flagged for not standing up straight, } \\
\text { removing their shoes, or changing } \\
\text { into examination gown during } \\
\text { measurements }\end{array}$ \\
\hline High blood pressure & $\begin{array}{l}\text { Have you ever been told by a doctor or } \\
\text { other health professional that you had } \\
\text { high blood pressure? }\end{array}$ & $\begin{array}{l}\text { Measured by health professionals. } \\
\text { After the participant rests quietly in a } \\
\text { sitting position for } 5 \text { minutes, three } \\
\text { consecutive blood pressure readings } \\
\text { are obtained ( } 4^{\text {th }} \text { measurement is } \\
\text { obtained if a blood pressure } \\
\text { measurement is interrupted or not } \\
\text { complete). Averaged } 4 \text { measurements } \\
\text { of systolic and diastolic pressures. }\end{array}$ & $\begin{array}{l}\text { Exclusion criteria: presence of the } \\
\text { following on both arms: rashes, } \\
\text { gauze dressings, casts, edema, } \\
\text { paralysis, tubes, open sores or } \\
\text { wounds, withered arms, a-v shunts, } \\
\text { or if blood has been drawn from arm } \\
\text { within the last week. }\end{array}$ \\
\hline
\end{tabular}


Table 1. Information on Self-Reported and Objectively Measured Health Data (continued)

\begin{tabular}{|c|c|c|c|}
\hline $\begin{array}{c}\text { Health } \\
\text { Behavior/Condition }\end{array}$ & Survey Question & Objective Tests & $\begin{array}{c}\text { Notes (eligible sample, exclusion } \\
\text { criteria etc.) }\end{array}$ \\
\hline LDL cholesterol & $\begin{array}{l}\text { Have you ever been told by a doctor or } \\
\text { other health professional that your } \\
\text { blood cholesterol was high? }\end{array}$ & $\begin{array}{l}\text { Measured with blood test: High LDL } \\
\text { ("bad") cholesterol defined as } 160 \\
\mathrm{mg} / \mathrm{dL} \text { or higher }\end{array}$ & $\begin{array}{l}\text { Test conducted only for those with } \\
\text { morning examination times }\end{array}$ \\
\hline Total cholesterol & $\begin{array}{l}\text { Have you ever been told by a doctor or } \\
\text { other health professional that your } \\
\text { blood cholesterol was high? }\end{array}$ & $\begin{array}{l}\text { Measured with blood test: High total } \\
\text { cholesterol defined as } 240 \mathrm{mg} / \mathrm{dL} \text { or } \\
\text { higher }\end{array}$ & \\
\hline $\begin{array}{l}\text { Diabetes } \\
\text { (glycohemoglobin } \\
\text { test) }\end{array}$ & $\begin{array}{l}\text { Other than during pregnancy, have you } \\
\text { ever been told by a doctor or health } \\
\text { professional that you have diabetes or } \\
\text { sugar diabetes? }\end{array}$ & $\begin{array}{l}\text { Measured with blood test. Diabetes } \\
\text { defined as glycohemoglobin (AIC \%) } \\
\text { of } 6.5 \text { or greater }\end{array}$ & \\
\hline $\begin{array}{l}\text { Diabetes (plasma } \\
\text { glucose test) }\end{array}$ & $\begin{array}{l}\text { Other than during pregnancy, have you } \\
\text { ever been told by a doctor or health } \\
\text { professional that you have diabetes or } \\
\text { sugar diabetes? }\end{array}$ & $\begin{array}{l}\text { Measured with blood test. Diabetes } \\
\text { defined as plasma glucose level of } \\
126 \mathrm{mg} / \mathrm{dL} \text { or greater }\end{array}$ & $\begin{array}{l}\text { Test conducted only for those with } \\
\text { morning examination times }\end{array}$ \\
\hline
\end{tabular}

Source: Centers for Disease Control and Prevention (CDC). National Center for Health Statistics (NCHS). National Health and Nutrition Examination Survey Questionnaire (or Examination Protocol, or Laboratory Protocol). Hyattsville, MD: U.S. Department of Health and Human Services, Centers for Disease Control and Prevention, 2015. http://www.cdc.gov/nchs/data/nhanes/pe.pdf Accessed June $3,2015$. 
Table 2. Unweighted Correlation Between Self-Reported and Objective Measures

\begin{tabular}{lc} 
Health Behavior or Condition & $\begin{array}{c}\text { Correlation Between Self-Report and } \\
\text { Measurement }\end{array}$ \\
\hline Smoking (test : cotinine $>=15 \mathrm{ng} / \mathrm{ml})$ & 0.904 \\
Smoking (test : cotinine $>=3 \mathrm{ng} / \mathrm{ml})$ & 0.918 \\
Obesity & 0.83 \\
High blood pressure & 0.701 \\
High LDL cholesterol & 0.595 \\
Total cholesterol & 0.579 \\
Diabetes (A1C test) & 0.786 \\
Diabetes (Glucose test) & 0.751 \\
\hline
\end{tabular}

Data: continuous NHANES 1999-2012 (pooled).

Note: Sample includes those who are 25 or older, completed both interview and examination components, and excludes those who have missing values for education and those who reported any of the survey data by a proxy respondent. For obesity, we exclude the data before 2003 cycle because it is uncertain whether any of the weight or height variables are reported by a proxy. Also, we exclude individuals who are pregnant, who refused to change into examination gown or did not stand up straight or wore shoes when examining weight and height. 
Table 3. Descriptive Statistics

\begin{tabular}{|c|c|c|c|}
\hline Accurate reporting of: & Mean & SD & $\mathbf{N}$ \\
\hline Smoking (cotinine $>=15 \mathrm{ng} / \mathrm{ml}$ ) & $96.6 \%$ & 0.18 & 20125 \\
\hline Smoking $($ cotinine $>=3 \mathrm{ng} / \mathrm{ml}$ ) & $97.1 \%$ & 0.17 & 20125 \\
\hline Obesity & $93.2 \%$ & 0.25 & 13822 \\
\hline High blood pressure & $86.8 \%$ & 0.34 & 21860 \\
\hline High cholesterol (LDL cholesterol) & $80.7 \%$ & 0.39 & 7513 \\
\hline High cholesterol (total cholesterol) & $80.3 \%$ & 0.4 & 16140 \\
\hline Diabetes (A1c) & $96.6 \%$ & 0.18 & 21576 \\
\hline Diabetes (plasma glucose) & $95.5 \%$ & 0.21 & 10539 \\
\hline \multicolumn{4}{|l|}{ False negative reporting of: } \\
\hline Smoking (cotinine $>=15 \mathrm{ng} / \mathrm{ml}$ ) & $4.2 \%$ & 0.2 & 4441 \\
\hline Smoking $($ cotinine $>=3 \mathrm{ng} / \mathrm{ml}$ ) & $6.5 \%$ & 0.25 & 4855 \\
\hline Obesity & $15.3 \%$ & 0.36 & 4962 \\
\hline High blood pressure & $23.7 \%$ & 0.43 & 8478 \\
\hline High cholesterol (LDL cholesterol) & $14.5 \%$ & 0.35 & 2402 \\
\hline High cholesterol (total cholesterol) & $18.7 \%$ & 0.39 & 5838 \\
\hline Diabetes (A1c) & $21.9 \%$ & 0.41 & 2554 \\
\hline Diabetes (plasma glucose) & $32.5 \%$ & 0.47 & 1414 \\
\hline \multicolumn{4}{|l|}{ False positive reporting of: } \\
\hline Smoking (cotinine $>=15 \mathrm{ng} / \mathrm{ml}$ ) & $3.2 \%$ & 0.18 & 15684 \\
\hline Smoking $($ cotinine $>=3 \mathrm{ng} / \mathrm{ml}$ ) & $1.6 \%$ & 0.12 & 15270 \\
\hline Obesity & $2.4 \%$ & 0.15 & 8860 \\
\hline High blood pressure & $8.2 \%$ & 0.27 & 13382 \\
\hline High cholesterol (LDL cholesterol) & $21.4 \%$ & 0.41 & 5111 \\
\hline High cholesterol (total cholesterol) & $20.2 \%$ & 0.4 & 10302 \\
\hline Diabetes (A1c) & $1.8 \%$ & 0.13 & 19022 \\
\hline Diabetes (plasma glucose) & $1.5 \%$ & 0.12 & 9125 \\
\hline
\end{tabular}


Data: continuous NHANES 1999-2010 (pooled) Note: Sample includes those who are 25 or older, completed both interview and examination components, and excludes those who have missing values for education and those who reported any of the survey data by a proxy respondent. For obesity, we exclude the data before 2003 cycle because it is uncertain whether any of the weight or height variables are reported by a proxy. Also, we exclude individuals who are pregnant, who refused to change into examination gown or did not stand up straight or wore shoes when examining weight and height. 
Table 4. Probit Models of Accurate Reporting

\begin{tabular}{|c|c|c|c|c|c|c|c|c|}
\hline & \multicolumn{2}{|c|}{ Smoking } & \multirow[t]{2}{*}{ Obesity } & \multirow{2}{*}{$\begin{array}{c}\text { High Blood } \\
\text { Pressure }\end{array}$} & \multicolumn{2}{|c|}{ High Cholesterol } & \multicolumn{2}{|c|}{ Diabetes } \\
\hline VARIABLES & $\begin{array}{c}\text { Cotinine } \\
>=15 \mathrm{ng} / \mathrm{ml}\end{array}$ & $\begin{array}{c}\text { Cotinine } \\
>=3 \mathrm{ng} / \mathrm{ml}\end{array}$ & & & High LDL & $\begin{array}{c}\text { Total } \\
\text { Cholesterol }\end{array}$ & A1C test & $\begin{array}{l}\text { Plasma } \\
\text { glucose }\end{array}$ \\
\hline Mean of Dep Var & 0.966 & 0.971 & 0.932 & 0.868 & 0.807 & 0.803 & 0.966 & 0.955 \\
\hline $\begin{array}{l}\text { Less than high } \\
\text { school }\end{array}$ & $\begin{array}{c}0.002 \\
(0.005)\end{array}$ & $\begin{array}{l}-0.005 \\
(0.006)\end{array}$ & $\begin{array}{l}-0.015 \\
(0.009)\end{array}$ & $\begin{array}{l}-0.007 \\
(0.011)\end{array}$ & $\begin{array}{c}0.015 \\
(0.021)\end{array}$ & $\begin{array}{l}-0.026 \\
(0.017)\end{array}$ & $\begin{array}{l}-0.003 \\
(0.004)\end{array}$ & $\begin{array}{c}0.002 \\
(0.006)\end{array}$ \\
\hline Some college & $\begin{array}{c}0.005 \\
(0.004)\end{array}$ & $\begin{array}{l}0.006 * \\
(0.003)\end{array}$ & $\begin{array}{l}-0.003 \\
(0.006)\end{array}$ & $\begin{array}{c}0.002 \\
(0.008)\end{array}$ & $\begin{array}{c}0.017 \\
(0.013)\end{array}$ & $\begin{array}{c}0.007 \\
(0.009)\end{array}$ & $\begin{array}{l}-0.001 \\
(0.002)\end{array}$ & $\begin{array}{c}0.007 \\
(0.005)\end{array}$ \\
\hline College graduate & $\begin{array}{c}0.007 * * \\
(0.003)\end{array}$ & $\begin{array}{c}0.010 * * * \\
(0.003)\end{array}$ & $\begin{array}{c}0.013 * * \\
(0.006)\end{array}$ & $\begin{array}{c}0.016 * * \\
(0.007)\end{array}$ & $\begin{array}{c}0.016 \\
(0.016)\end{array}$ & $\begin{array}{c}0.016 \\
(0.011)\end{array}$ & $\begin{array}{c}0.008 * * * \\
(0.003)\end{array}$ & $\begin{array}{c}0.016 * * * \\
(0.005)\end{array}$ \\
\hline Observations & 18,946 & 19,040 & 13261 & 20,801 & 7,098 & 15,277 & 20,099 & 9,827 \\
\hline
\end{tabular}

Standard errors in parentheses $* * * \mathrm{p}<0.01, * * \mathrm{p}<0.05, * \mathrm{p}<0.10$. [Data: Continuous NHANES 1999-2010 (pooled)]

Notes: All regressions control for indicator variables for survey year, gender, age, race/ethnicity, citizenship status, whether English is the primary language spoken at home, and education categories (omitted category: high school graduate, other race), and the difference between age in months at screening and at examination. For smoking regressions, we control for whether anyone in the household smokes to account for second hand smoking. Cotinine cutoff for smoking status: $15 \mathrm{ng} / \mathrm{ml}, 3 \mathrm{ng} / \mathrm{ml}$ respectively.

This table reports marginal effects from probit models. Regression sample includes those who are 25 or older, completed both interview and examination components, and excludes those who have missing values for education and those who reported any of the survey data by a proxy respondent. Because age at examination is not provided for 2011-12 wave and data from this wave is excluded from the regression sample. For obesity, we exclude the data before 2003 cycle because it is uncertain whether any of the weight or height variables are reported by a proxy. Also, we exclude individuals who refused to change into examination gown or did not stand up straight or wore shoes when examining weight and height. 
Table 5. Probit Models of False Negative Reporting

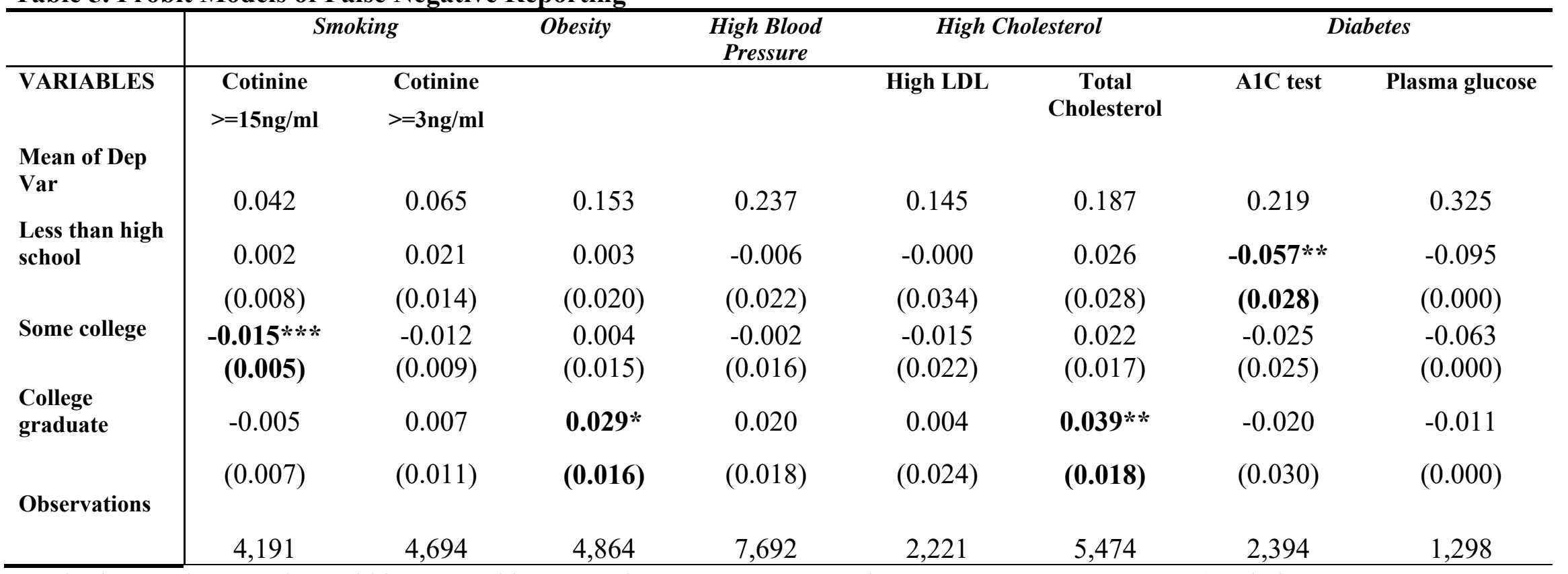

Standard errors in parentheses $* * * \mathrm{p}<0.01, * * \mathrm{p}<0.05, * \mathrm{p}<0.10$. [Data: Continuous NHANES 1999-2010 (pooled)]

Notes: All regressions control for indicator variables for survey year, gender, age, race/ethnicity, citizenship status, whether English is the primary language spoken at home, and education categories (omitted category: high school graduate, other race), and the difference between age in months at screening and at examination. For smoking regressions, we control for whether anyone in the household smokes to account for second hand smoking. Cotinine cutoff for smoking status: $15 \mathrm{ng} / \mathrm{ml}, 3 \mathrm{ng} / \mathrm{ml}$ respectively

This table reports marginal effects from probit models. Regression sample includes those who are 25 or older, completed both interview and examination components, and excludes those who have missing values for education and those who reported any of the survey data by a proxy respondent. Because age at examination is not provided for 2011-12 wave and data from this wave is excluded from the regression sample. For obesity, we exclude the data before 2003 cycle because it is uncertain whether any of the weight or height variables are reported by a proxy. Also, we exclude individuals who refused to change into examination gown or did not stand up straight or wore shoes when examining weight and height. 
Table 6. Probit Models of False Positive Reporting

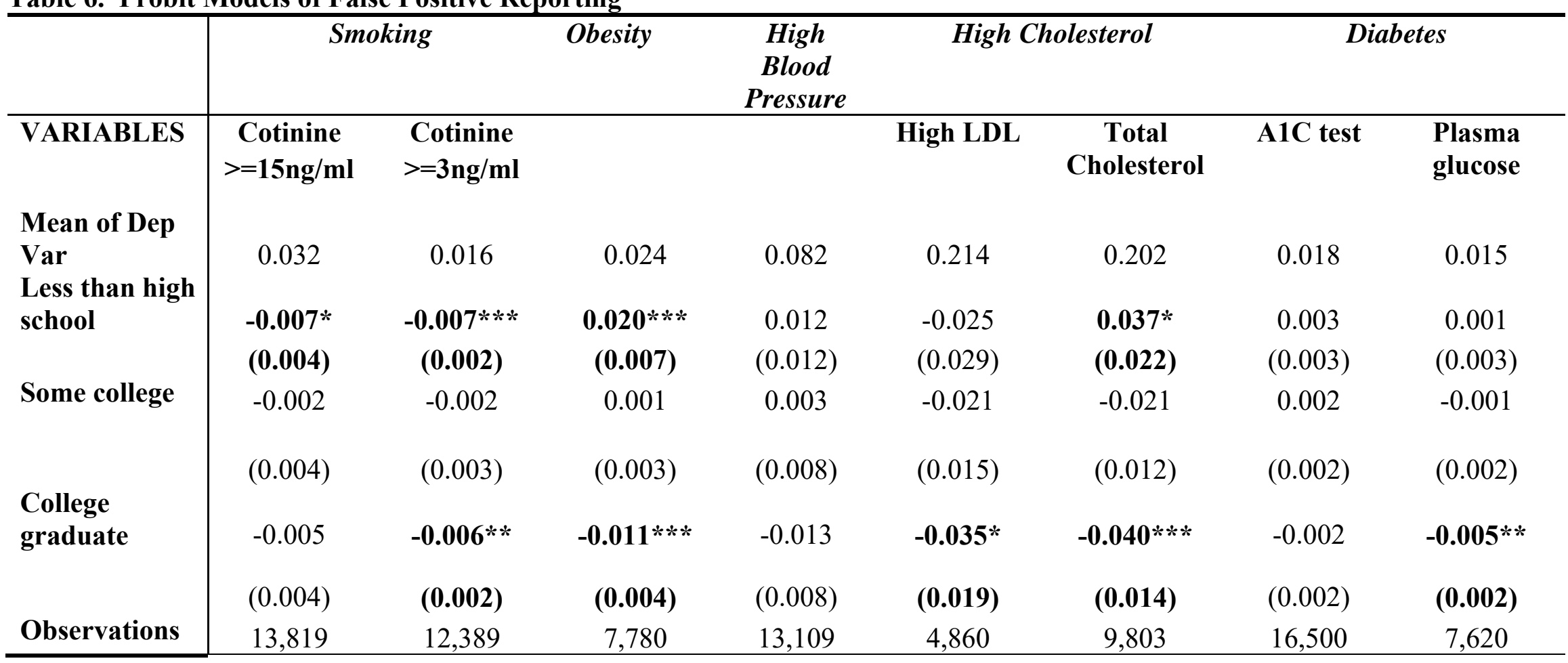

Standard errors in parentheses $* * * p<0.01, * * p<0.05, * \mathrm{p}<0.10$. [Data:Continuous NHANES 1999-2010 (pooled)]

Notes: All regressions control for indicator variables for survey year, gender, age, race/ethnicity, citizenship status, whether English is the primary language spoken at home, and education categories (omitted category: high school graduate, other race), and the difference between age in months at screening and at examination. For smoking regressions, we control for whether anyone in the household smokes to account for second hand smoking. Cotinine cutoff for smoking status: $15 \mathrm{ng} / \mathrm{ml}, 3 \mathrm{ng} / \mathrm{ml}$ respectively

This table reports marginal effects from probit models. Regression sample includes those who are 25 or older, completed both interview and examination components, and excludes those who have missing values for education and those who reported any of the survey data by a proxy respondent. Because age at examination is not provided for 2011-12 wave and data from this wave is excluded from the regression sample. For obesity, we exclude the data before 2003 cycle because it is uncertain whether any of the weight or height variables are reported by a proxy. Also, we exclude individuals who refused to change into examination gown or did not stand up straight or wore shoes when examining weight and height. 
Table 7. Health Disparities Across Education: (High School Graduate or Less) vs. (Some College or More)

\begin{tabular}{l|cccc}
\hline Health Conditions/Behaviors & $\begin{array}{c}\text { Disparity in } \\
\text { self-reported values }\end{array}$ & $\begin{array}{c}\text { Disparity in } \\
\text { measured values }\end{array}$ & $\begin{array}{c}\text { \% point } \\
\text { difference }\end{array}$ \\
\hline High total Cholesterol & 0.082 & 0.052 & 0.030 & \% difference \\
High LDL Cholesterol & 0.082 & 0.064 & 0.018 & 57.692 \\
Obesity & 0.056 & 0.048 & 0.008 & 16.667 \\
Smoking (cotinine>=15 ng/ml) & 0.113 & 0.122 & -0.009 & -7.377 \\
Smoking (cotinine>=3ng/ml) & 0.113 & 0.124 & -0.011 & -8.871 \\
Diabetes (AIC test) & 0.041 & 0.045 & -0.004 & -8.889 \\
High blood pressure & 0.072 & 0.096 & -0.024 & -25.000 \\
Diabetes (Glucose test) & 0.041 & 0.057 & -0.016 & -28.070 \\
\hline Average & & & & 3.035 \\
\hline
\end{tabular}

Data: continuous NHANES 1999-2012 (pooled)

Note: Sample includes those who are 25 or older, completed both interview and examination components, and excludes those who have missing values for education and those who reported any of the survey data by a proxy respondent. For obesity, we exclude the data before 2003 cycle because it is uncertain whether any of the weight or height variables are reported by a proxy. Also, we exclude individuals who refused to change into examination gown or did not stand up straight or wore shoes when examining weight and height. Reports and measures of high cholesterol, high blood pressure, and diabetes are not adjusted to account for fact that some individuals are taking medications for those conditions (the accuracy measures that serve as dependent variables in the regression models do take medication use into account). 
Table 8. Probit Models of Accurate Reporting

(controlling for health insurance, any doctor's visit, any hospitalization last year)

\begin{tabular}{|c|c|c|c|c|c|c|c|c|}
\hline & \multicolumn{2}{|c|}{ Smoking } & \multirow[t]{2}{*}{ Obesity } & \multirow{2}{*}{$\begin{array}{c}\text { High blood } \\
\text { pressure }\end{array}$} & \multicolumn{2}{|c|}{ High Cholesterol } & \multicolumn{2}{|c|}{ Diabetes } \\
\hline VARIABLES & $\begin{array}{c}\text { Cotinine } \\
>=15 \mathrm{ng} / \mathrm{ml}\end{array}$ & $\begin{array}{l}\text { Cotinine } \\
>=3 \mathrm{ng} / \mathrm{ml}\end{array}$ & & & $\begin{array}{l}\text { High } \\
\text { LDL }\end{array}$ & $\begin{array}{c}\text { Total } \\
\text { Cholesterol }\end{array}$ & A1C test & $\begin{array}{l}\text { Plasma } \\
\text { glucose }\end{array}$ \\
\hline Mean of Dep Var & 0.966 & 0.971 & 0.932 & 0.868 & 0.807 & 0.803 & 0.966 & 0.955 \\
\hline $\begin{array}{l}\text { Less than high } \\
\text { school }\end{array}$ & $\begin{array}{c}0.003 \\
(0.005)\end{array}$ & $\begin{array}{l}-0.003 \\
(0.005)\end{array}$ & $\begin{array}{l}-0.012 \\
(0.009)\end{array}$ & $\begin{array}{l}-0.001 \\
(0.011)\end{array}$ & $\begin{array}{c}0.014 \\
(0.022)\end{array}$ & $\begin{array}{l}-0.023 \\
(0.017)\end{array}$ & $\begin{array}{c}-0.002 \\
(0.004)\end{array}$ & $\begin{array}{c}0.003 \\
(0.005)\end{array}$ \\
\hline Some college & $\begin{array}{c}0.005 \\
(0.004)\end{array}$ & $\begin{array}{l}0.005 * \\
(0.003)\end{array}$ & $\begin{array}{l}-0.004 \\
(0.006)\end{array}$ & $\begin{array}{l}-0.001 \\
(0.008)\end{array}$ & $\begin{array}{c}0.018 \\
(0.013)\end{array}$ & $\begin{array}{c}0.006 \\
(0.010)\end{array}$ & $\begin{array}{l}-0.001 \\
(0.002)\end{array}$ & $\begin{array}{c}0.007 \\
(0.005)\end{array}$ \\
\hline College graduate & $\begin{array}{l}0.006 * \\
(0.003)\end{array}$ & $\begin{array}{c}0.009 * * * \\
(0.003)\end{array}$ & $\begin{array}{l}0.011 * \\
(0.006)\end{array}$ & $\begin{array}{c}0.010 \\
(0.007)\end{array}$ & $\begin{array}{r}0.017 \\
(0.016)\end{array}$ & $\begin{array}{c}0.014 \\
(0.011)\end{array}$ & $\begin{array}{c}0.007 * * * \\
(0.003)\end{array}$ & $\begin{array}{c}0.014 * * * \\
(0.005)\end{array}$ \\
\hline Observations & 18,933 & 19,027 & 13,253 & 20,783 & 7,093 & 15,269 & 20,083 & 9,818 \\
\hline
\end{tabular}

Standard errors in parentheses $* * * \mathrm{p}<0.01, * * \mathrm{p}<0.05, * \mathrm{p}<0.10$. [Data:Continuous NHANES 1999-2010 (pooled)]

Notes: All regressions control for indicator variables for survey year, gender, age, race/ethnicity, citizenship status, whether English is the primary language spoken at home, and education categories (omitted category: high school graduate, other race), and the difference between age in months at screening and at examination. For smoking regressions, we control for whether anyone in the household smokes to account for second hand smoking. Cotinine cutoff for smoking status: $15 \mathrm{ng} / \mathrm{ml}, 3 \mathrm{ng} / \mathrm{ml}$ respectively

This table reports marginal effects from probit models. Regression sample includes those who are 25 or older, completed both interview and examination components, and excludes those who have missing values for education and those who reported any of the survey data by a proxy respondent. Because age at examination is not provided for 2011-12 wave and data from this wave is excluded from the regression sample. For obesity, we exclude the data before 2003 cycle because it is uncertain whether any of the weight or height variables are reported by a proxy. Also, we exclude individuals who refused to change into examination gown or did not stand up straight or wore shoes when examining weight and height. 
Table 9. Probit Models of False Negative Reporting

(controlling for health insurance, any doctor's visit, any hospitalization last year)

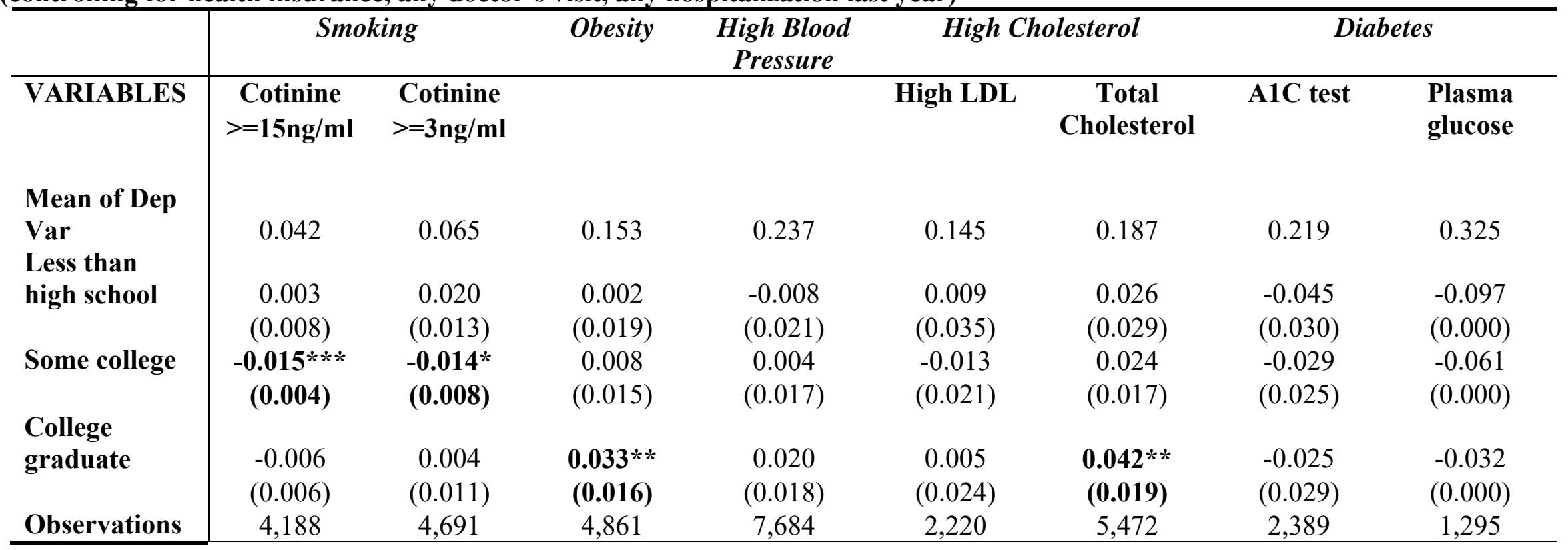

Standard errors in parentheses $* * * \mathrm{p}<0.01, * * \mathrm{p}<0.05, * \mathrm{p}<0.10$. [Data:Continuous NHANES 1999-2010 (pooled)]

Notes: All regressions control for indicator variables for survey year, gender, age, race/ethnicity, citizenship status, whether English is the primary language spoken at home, and education categories (omitted category: high school graduate, other race), and the difference between age in months at screening and at examination. For smoking regressions, we control for whether anyone in the household smokes to account for second hand smoking. Cotinine cutoff for smoking status: $15 \mathrm{ng} / \mathrm{ml}, 3 \mathrm{ng} / \mathrm{ml}$ respectively

This table reports marginal effects from probit models. Regression sample includes those who are 25 or older, completed both interview and examination components, and excludes those who have missing values for education and those who reported any of the survey data by a proxy respondent. Because age at examination is not provided for 2011-12 wave and data from this wave is excluded from the regression sample. For obesity, we exclude the data before 2003 cycle because it is uncertain whether any of the weight or height variables are reported by a proxy. Also, we exclude individuals who refused to change into examination gown or did not stand up straight or wore shoes when examining weight and height. 
Table 10. Probit Models of False Positive Reporting

(controlling for health insurance, any doctor's visit, any hospitalization last year)

\begin{tabular}{|c|c|c|c|c|c|c|c|c|}
\hline & \multicolumn{2}{|c|}{ Smoking } & \multirow[t]{2}{*}{ Obesity } & \multirow{2}{*}{$\begin{array}{l}\text { High Blood } \\
\text { Pressure }\end{array}$} & \multicolumn{2}{|c|}{ High Cholesterol } & \multicolumn{2}{|c|}{ Diabetes } \\
\hline VARIABLES & $\begin{array}{c}\text { Cotinine } \\
>=15 \mathrm{ng} / \mathrm{ml}\end{array}$ & $\begin{array}{c}\text { Cotinine } \\
>=3 \mathrm{ng} / \mathrm{ml}\end{array}$ & & & $\begin{array}{l}\text { High } \\
\text { LDL }\end{array}$ & $\begin{array}{c}\text { Total } \\
\text { Cholesterol }\end{array}$ & $\begin{array}{c}\text { A1C } \\
\text { test }\end{array}$ & $\begin{array}{l}\text { Plasma } \\
\text { glucose }\end{array}$ \\
\hline Mean of Dep Var & 0.032 & 0.016 & 0.024 & 0.082 & 0.214 & 0.202 & 0.018 & 0.015 \\
\hline Less than high school & $\begin{array}{c}-0.009 * * \\
(0.004)\end{array}$ & $\begin{array}{c}-0.007 * * * \\
(0.002)\end{array}$ & $\begin{array}{c}0.018 * * * \\
(0.006)\end{array}$ & $\begin{array}{c}0.006 \\
(0.011)\end{array}$ & $\begin{array}{l}-0.024 \\
(0.029)\end{array}$ & $\begin{array}{c}0.034 \\
(0.021)\end{array}$ & $\begin{array}{c}0.001 \\
(0.002)\end{array}$ & $\begin{array}{l}-0.001 \\
-0.002\end{array}$ \\
\hline Some college & $\begin{array}{l}-0.001 \\
(0.004)\end{array}$ & $\begin{array}{l}-0.002 \\
(0.003)\end{array}$ & $\begin{array}{c}0.001 \\
(0.003)\end{array}$ & $\begin{array}{c}0.003 \\
(0.008)\end{array}$ & $\begin{array}{l}-0.021 \\
(0.015)\end{array}$ & $\begin{array}{l}-0.020 \\
(0.013)\end{array}$ & $\begin{array}{c}0.001 \\
(0.002)\end{array}$ & $\begin{array}{c}0 \\
-0.002\end{array}$ \\
\hline College graduate & $\begin{array}{l}-0.004 \\
(0.004)\end{array}$ & $\begin{array}{c}-0.005 * * \\
(0.002)\end{array}$ & $\begin{array}{c}-0.009 * * \\
(0.003)\end{array}$ & $\begin{array}{l}-0.009 \\
(0.008)\end{array}$ & $\begin{array}{l}-0.036 * \\
(0.020)\end{array}$ & $\begin{array}{c}-0.038 * * * \\
(0.014)\end{array}$ & $\begin{array}{l}-0.001 \\
(0.002)\end{array}$ & $\begin{array}{l}-0.004 * \\
(0.002)\end{array}$ \\
\hline Observations & 13,809 & 12,382 & 7,776 & 13,099 & 4,856 & 9,797 & 16,490 & 7,616 \\
\hline
\end{tabular}

Standard errors in parentheses $* * * \mathrm{p}<0.01, * * \mathrm{p}<0.05, * \mathrm{p}<0.10$. [Data:Continuous NHANES 1999-2010 (pooled)]

Notes: All regressions control for indicator variables for survey year, gender, age, race/ethnicity, citizenship status, whether English is the primary language spoken at home, and education categories (omitted category: high school graduate, other race), and the difference between age in months at screening and at examination. For smoking regressions, we control for whether anyone in the household smokes to account for second hand smoking. Cotinine cutoff for smoking status: $15 \mathrm{ng} / \mathrm{ml}, 3 \mathrm{ng} / \mathrm{ml}$ respectively

This table reports marginal effects from probit models. Regression sample includes those who are 25 or older, completed both interview and examination components, and excludes those who have missing values for education and those who reported any of the survey data by a proxy respondent. Because age at examination is not provided for 2011-12 wave and data from this wave is excluded from the regression sample. For obesity, we exclude the data before 2003 cycle because it is uncertain whether any of the weight or height variables are reported by a proxy. Also, we exclude individuals who refused to change into examination gown or did not stand up straight or wore shoes when examining weight and height. 
Table 11. Percent of respondents who refused to answer or reported "don't know"

\begin{tabular}{|c|c|c|c|c|c|}
\hline Health Conditions / Behaviors & $\%$ Refused & \% Don't know & Refusals (N) & Don't know (N) & Total sample size \\
\hline Smoking & 0 & 0 & 0 & 0 & 21114 \\
\hline High blood pressure & 0 & 0.15 & 0 & 34 & 23019 \\
\hline High Cholesterol & 0 & 0.75 & 1 & 129 & 17183 \\
\hline Diabetes & 0 & 0.06 & 0 & 14 & 22717 \\
\hline Weight & 0.03 & 0.94 & 5 & 150 & 15930 \\
\hline Height & 0.01 & 1.41 & 1 & 224 & 15894 \\
\hline
\end{tabular}

Data: continuous NHANES 1999-2010 (pooled)

Note: Sample includes those who are 25 or older, completed both interview and examination components, and excludes those who have missing values for education and those who reported any of the survey data by a proxy respondent. For obesity, we exclude the data before 2003 cycle because it is uncertain whether any of the weight or height variables are reported by a proxy. Also, we exclude individuals who refused to change into examination gown or did not stand up straight or wore shoes when examining weight and height. Reports unweighted percents (\%). 
Table 12. Probit Models for Refusing, Saying Didn't Know

\begin{tabular}{|c|c|c|c|c|c|c|c|c|c|c|}
\hline Variables & $\begin{array}{r}\text { Refus } \\
\text { exam }\end{array}$ & $\begin{array}{l}\text { entire } \\
\text { ation }\end{array}$ & $\begin{array}{r}\text { Refuse } \\
w\end{array}$ & $\begin{array}{l}\text { o report } \\
\text { ght }\end{array}$ & $\begin{array}{r}\text { Don } \\
(w\end{array}$ & $\begin{array}{l}\text { know } \\
\text { ght) }\end{array}$ & & $\begin{array}{l}\text { know } \\
\text { ht) }\end{array}$ & $\begin{array}{l}\text { Don } \\
\text { (high }\end{array}$ & $\begin{array}{l}\text { t know } \\
\text { holesterol) }\end{array}$ \\
\hline Mean of Dep Var & & & & & & & & & & 065 \\
\hline & Probit & Probit & LPM & LPM & Probit & Probit & Probit & Probit & Probit & Probit \\
\hline $\begin{array}{l}\text { Less than high } \\
\text { school }\end{array}$ & 0.008 & 0.007 & -0.000 & -0.000 & $0.003 * *$ & $0.002 * *$ & $0.002 *$ & $0.001 *$ & 0.002 & 0.001 \\
\hline & $(0.006)$ & $(0.006)$ & $(0.000)$ & $(0.000)$ & $(0.001)$ & $(0.001)$ & $(0.001)$ & $(0.001)$ & $(0.003)$ & $(0.003)$ \\
\hline Some college & 0.002 & 0.002 & -0.000 & 0.000 & 0.000 & -0.000 & -0.000 & -0.000 & $-0.003 * *$ & $-0.003 * *$ \\
\hline & $(0.004)$ & $(0.004)$ & $(0.000)$ & $(0.001)$ & $(0.001)$ & $(0.001)$ & $(0.000)$ & $(0.000)$ & $(0.001)$ & $(0.001)$ \\
\hline College graduate & $0.009 * *$ & $0.010 * *$ & -0.000 & -0.000 & $-0.002 * * *$ & $-0.001 *$ & $-0.000 *$ & -0.000 & $-0.003 *$ & -0.002 \\
\hline & $(0.005)$ & $(0.004)$ & $(0.000)$ & $(0.000)$ & (0.001) & (0.001) & $(0.000)$ & $(0.000)$ & $(0.002)$ & $(0.002)$ \\
\hline $\begin{array}{l}\text { Control for health } \\
\text { insurance and health } \\
\text { care utilization }\end{array}$ & $\mathrm{N}$ & $\mathrm{Y}$ & $\mathrm{N}$ & $\mathrm{Y}$ & $\mathrm{N}$ & $\mathrm{Y}$ & $\mathrm{N}$ & $\mathrm{Y}$ & $\mathrm{N}$ & $\mathrm{Y}$ \\
\hline Observations & 24,357 & 24,328 & 15,048 & 15,038 & 13,217 & 13,208 & 14,521 & 14,512 & 12,245 & 12,240 \\
\hline
\end{tabular}

Standard errors in parentheses $* * * \mathrm{p}<0.01, * * \mathrm{p}<0.05, * \mathrm{p}<0.10$. [Data:Continuous NHANES 1999-2010 (pooled)]

Notes: All regressions control for indicator variables for survey year, gender, age, race/ethnicity, citizenship status, whether English is the primary language spoken at home, and education categories (omitted category: high school graduate, other race), and the difference between age in months at screening and at examination. For smoking regressions, we control for whether anyone in the household smokes to account for second hand smoking. Cotinine cutoff for smoking status: $15 \mathrm{ng} / \mathrm{ml}, 3 \mathrm{ng} / \mathrm{ml}$ respectively

Sample includes those who are 25 or older, completed both interview and examination components, and excludes those who have missing values for education and those who reported any of the survey data by a proxy respondent. Because age at examination is not provided for 2011-12 wave and data from this wave is excluded from the regression sample. For obesity, we exclude the data before 2003 cycle because it is uncertain whether any of the weight or height variables are reported by a proxy. Also, we exclude individuals who refused to change into examination gown or did not stand up straight or wore shoes when examining weight and height. Report Marginal effects from Probit models except for linear probability models of weight refusals (due to very few positive refused responses probit models do not converge). $\mathrm{DV}=1$ if respondent only participated in the interview but not the examination component and 0 otherwise, $\mathrm{DV}=1$ if refused to respond (or report don't know) for survey questionnaires and 0 otherwise) 
Table 13. Probit models of recent measurements of blood pressure and cholesterol

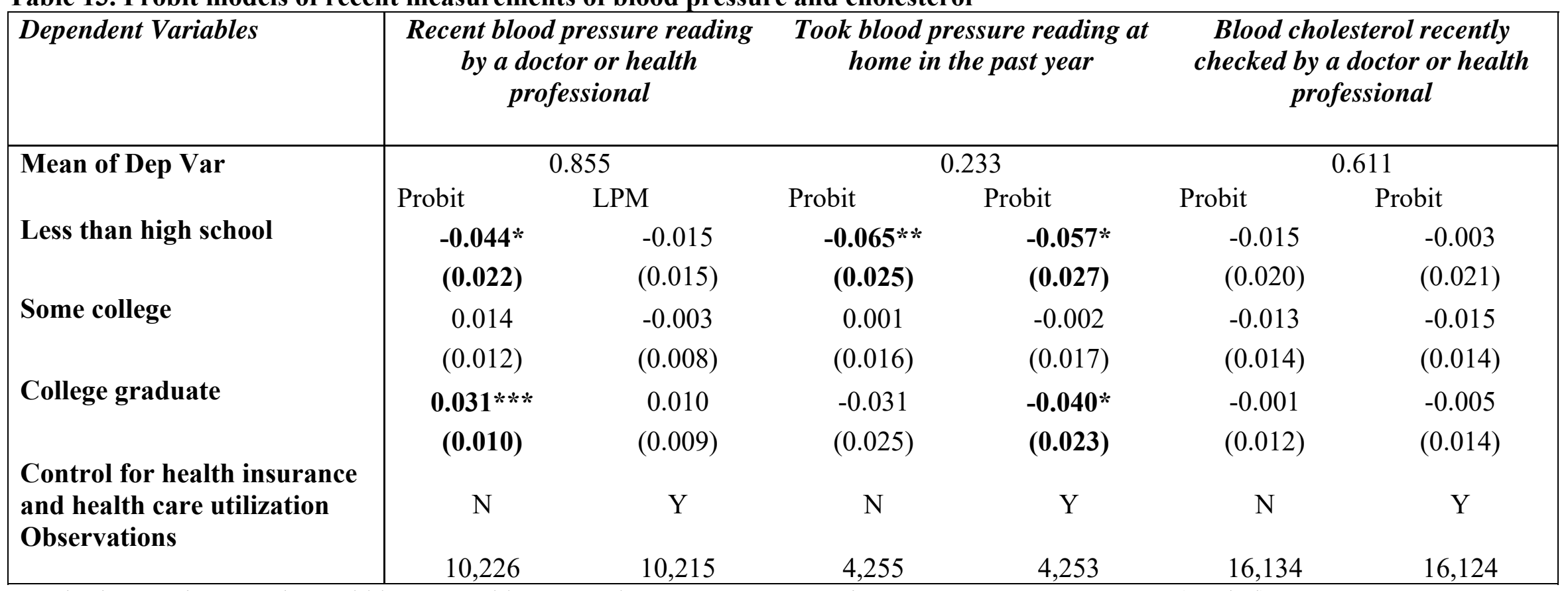

Standard errors in parentheses $* * * \mathrm{p}<0.01, * * \mathrm{p}<0.05, * \mathrm{p}<0.10$. [Data:Continuous NHANES 1999-2010 (pooled)]

Notes: All regressions control for indicator variables for survey year, gender, age, race/ethnicity, citizenship status, whether English is the primary language spoken at home, and education categories (omitted category: high school graduate, other race), and the difference between age in months at screening and at examination. Report Marginal effects from Probit models except for columns that says LPM (Linear probability model)

Sample includes those who are 25 or older, completed both interview and examination components, and excludes those who have missing values for education and those who reported any of the survey data by a proxy respondent. Because age at examination is not provided for 2011-12 wave and data from this wave is excluded from the regression sample.

DV (first and third column) $=1$ if respondent reported that they had their blood pressure or cholesterol checked less than a year ago and 0 if checked more than 1 year ago. DV (second column, blood pressure reading at home) $=1$ if the respondent took the measurement at home in the past 12 months, and 0 if not. 
Table 14. Probit models of Accurate, False Negative and False Positive reporting of high blood pressure (controlling for whether the respondent had a blood pressure reading by a doctor within the past year)

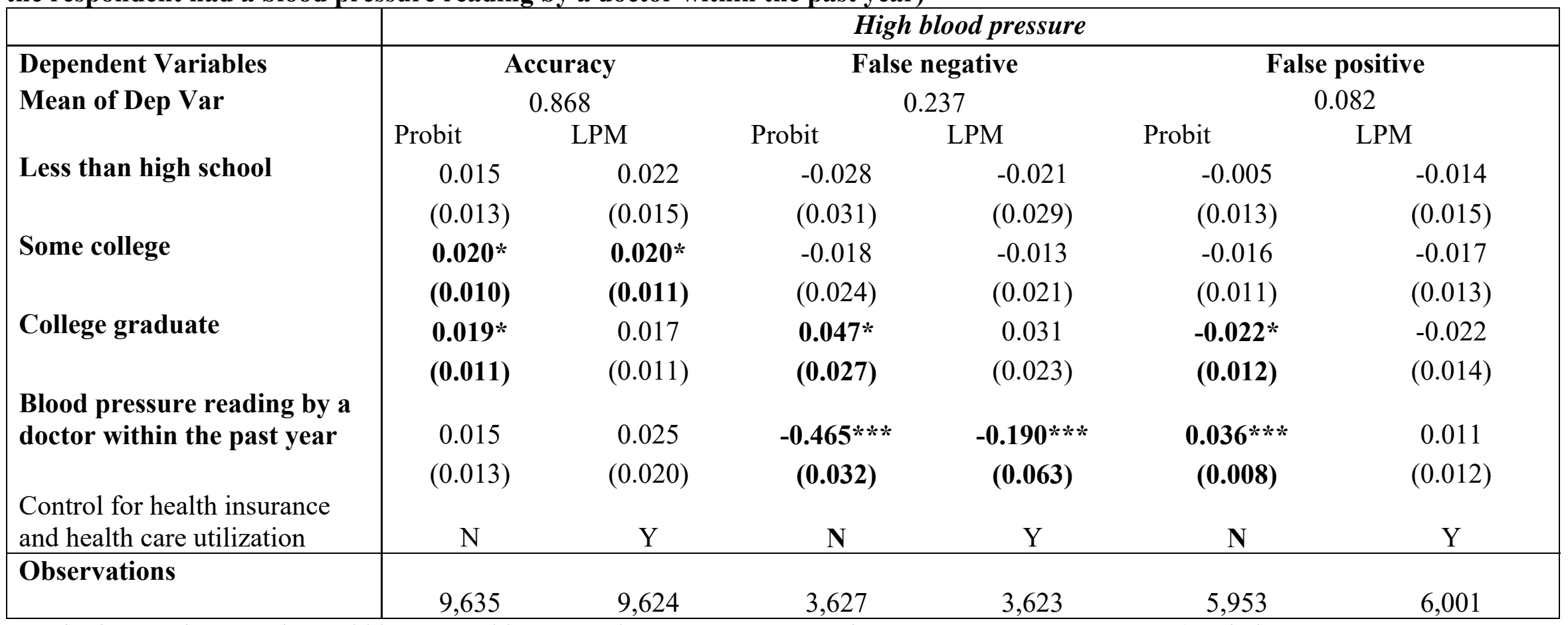

Standard errors in parentheses $* * * p<0.01, * * p<0.05, * p<0.10$. [Data:Continuous NHANES 1999-2010 (pooled)]

Notes: All regressions control for indicator variables for survey year, gender, age, race/ethnicity, citizenship status, whether English is the primary language spoken at home, and education categories (omitted category: high school graduate, other race), and the difference between age in months at screening and at examination. Report Marginal effects from Probit models except for columns that says LPM (Linear probability model)

Sample includes those who are 25 or older, completed both interview and examination components, and excludes those who have missing values for education and those who reported any of the survey data by a proxy respondent. Because age at examination is not provided for 2011-12 wave and data from this wave is excluded from the regression sample. 
Table 15. Probit models of Accurate, False Negative and False Positive reporting of high blood pressure (controlling for whether the respondent checked the blood pressure at home within the past year)

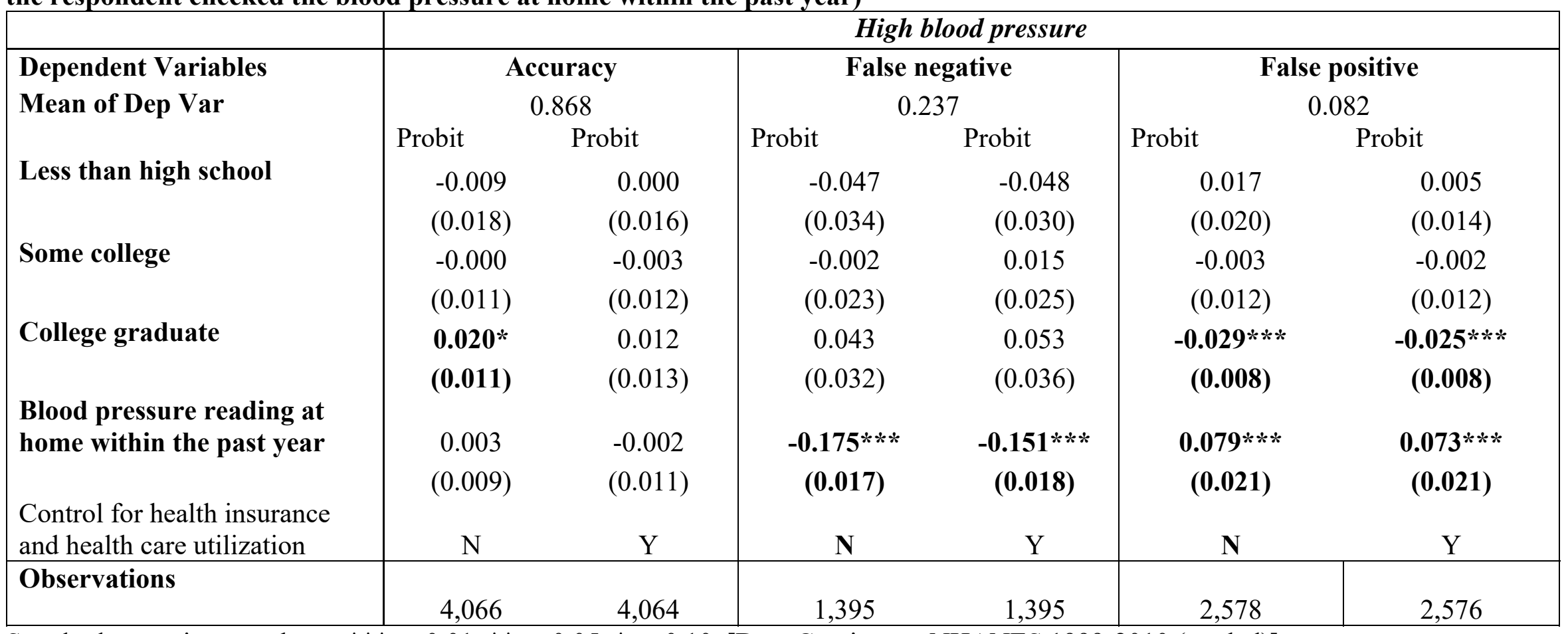

Standard errors in parentheses $* * * p<0.01, * * p<0.05, * p<0.10$. [Data:Continuous NHANES 1999-2010 (pooled)]

Notes: All regressions control for indicator variables for survey year, gender, age, race/ethnicity, citizenship status, whether English is the primary language spoken at home, and education categories (omitted category: high school graduate, other race), and the difference between age in months at screening and at examination. Report Marginal effects from Probit models.

Sample includes those who are 25 or older, completed both interview and examination components, and excludes those who have missing values for education and those who reported any of the survey data by a proxy respondent. Because age at examination is not provided for 2011-12 wave and data from this wave is excluded from the regression sample. 
Table 16. Probit models of Accurate, False Negative and False Positive reporting of diabetes (controlling for respondent's family history of diabetes)

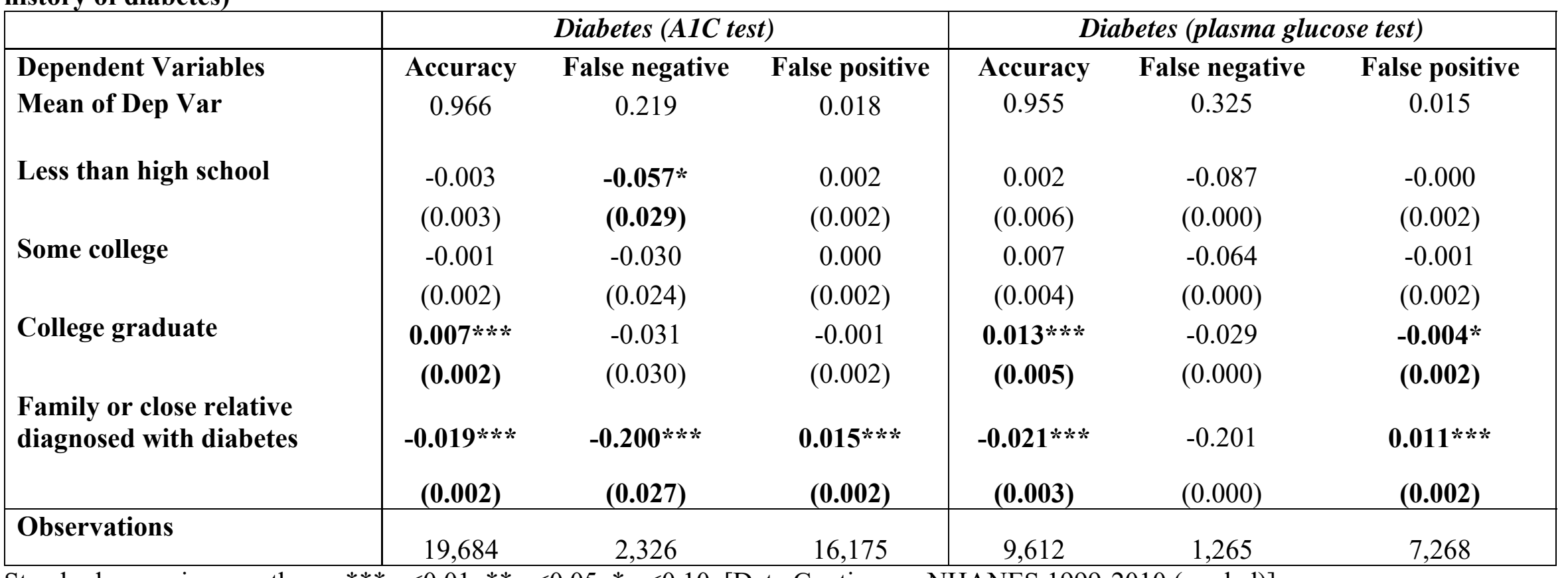

Standard errors in parentheses $* * * p<0.01, * * \mathrm{p}<0.05, * \mathrm{p}<0.10$. [Data:Continuous NHANES 1999-2010 (pooled)]

Notes: All regressions control for indicator variables for survey year, gender, age, race/ethnicity, citizenship status, whether English is the primary language spoken at home, and education categories (omitted category: high school graduate, other race), and the difference between age in months at screening and at examination. Report Marginal effects from Probit models.

Sample includes those who are 25 or older, completed both interview and examination components, and excludes those who have missing values for education and those who reported any of the survey data by a proxy respondent. Because age at examination is not provided for 2011-12 wave and data from this wave is excluded from the regression sample. 
Table 17. Probit models of Accurate, False Negative and False Positive reporting of high cholesterol (controlling for respondent's family history of heart attack or angina before the age of 50)

\begin{tabular}{|c|c|c|c|c|c|c|}
\hline & \multicolumn{3}{|c|}{ High LDL cholesterol } & \multicolumn{3}{|c|}{ High total cholesterol } \\
\hline Dependent Variables & Accuracy & False negative & False positive & Accuracy & False negative & False positive \\
\hline Mean of Dep Var & 0.807 & 0.145 & 0.214 & 0.803 & 0.187 & 0.202 \\
\hline Less than high school & $(0.022)$ & $(0.035)$ & $(0.029)$ & $(0.018)$ & $(0.028)$ & $(0.022)$ \\
\hline Some college & 0.010 & -0.008 & -0.015 & 0.004 & 0.025 & -0.018 \\
\hline \multirow[t]{2}{*}{ College graduate } & 0.015 & 0.002 & $-0.034 \%$ & 0.015 & $0.039 * *$ & $-0.038 * * *$ \\
\hline & $(0.016)$ & $(0.024)$ & $(0.019)$ & $(0.012)$ & $(0.019)$ & $(0.014)$ \\
\hline \multirow[t]{2}{*}{$\begin{array}{l}\text { Family or close relative had a } \\
\text { heart condition }\end{array}$} & 0.014 & $-0.062 * * *$ & 0.017 & 0.004 & $-0.071 * * *$ & $0.031 * *$ \\
\hline & $(0.016)$ & $(0.020)$ & $(0.022)$ & $(0.010)$ & $(0.012)$ & $(0.015)$ \\
\hline
\end{tabular}

Standard errors in parentheses $* * * p<0.01, * * p<0.05, * p<0.10$. [Data:Continuous NHANES 1999-2010 (pooled)]

Notes: All regressions control for indicator variables for survey year, gender, age, race/ethnicity, citizenship status, whether English is the primary language spoken at home, and education categories (omitted category: high school graduate, other race), and the difference between age in months at screening and at examination. Report Marginal effects from Probit models.

Sample includes those who are 25 or older, completed both interview and examination components, and excludes those who have missing values for education and those who reported any of the survey data by a proxy respondent. Because age at examination is not provided for 2011-12 wave and data from this wave is excluded from the regression sample. 